\title{
Instruments, Randomization, and Learning about Development
}

\author{
ANGUS DEATON ${ }^{\text {困 }}$
}

There is currently much debate about the effectiveness of foreign aid and about what kind of projects can engender economic development. There is skepticism about the ability of econometric analysis to resolve these issues or of development agencies to learn from their own experience. In response, there is increasing use in development economics of randomized controlled trials (RCTs) to accumulate credible knowledge of what works, without overreliance on questionable theory or statistical methods. When RCTs are not possible, the proponents of these methods advocate quasirandomization through instrumental variable (IV) techniques or natural experiments. I argue that many of these applications are unlikely to recover quantities that are useful for policy or understanding: two key issues are the misunderstanding of exogeneity and the handling of heterogeneity. I illustrate from the literature on aid and growth. Actual randomization faces similar problems as does quasi-randomization, notwithstanding rhetoric to the contrary. I argue that experiments have no special ability to produce more credible knowledge than other methods, and that actual experiments are frequently subject to practical problems that undermine any claims to statistical or epistemic superiority. I illustrate using prominent experiments in development and elsewhere. As with IV methods, RCT-based evaluation of projects, without guidance from an understanding of underlying mechanisms, is unlikely to lead to scientific progress in the understanding of economic development. I welcome recent trends in development experimentation away from the evaluation of projects and toward the evaluation of theoretical mechanisms. (JEL C21, F35, O19)

\footnotetext{
* Deaton: Princeton University. This is a lightly revised and updated version of "Instruments of Development: Randomization in the Tropics and the Search for the Elusive Keys to Economic Development," originally given as the Keynes Lecture, British Academy, October 9, 2008, and published in the Proceedings of the British Academy 102, 2008 Lectures, () The British Academy 2009. I am grateful to the British Academy for permission to reprint the unchanged material. I have clarified some points in response to Imbens (2009), but have not changed anything of substance and stand by my original arguments. For helpful discussions and comments on earlier versions, I am grateful to Abhijit Banerjee, Tim Besley, Richard Blundell,
}

Ron Brookmayer, David Card, Anne Case, Hank Farber, Bill Easterly, Erwin Diewert, Jean Drèze, Esther Duflo, Ernst Fehr, Don Green, Jim Heckman, Ori Heffetz, Karla Hoff, Bo Honoré, Štěpán Jurajda, Dean Karlan, Aart Kraay, Michael Kremer, David Lee, Steve Levitt, Winston Lin, John List, David McKenzie, Margaret McMillan, Costas Meghir, Branko Milanovic, Chris Paxson, Franco Peracchi, Dani Rodrik, Sam Schulhofer-Wohl, Jonathan Skinner, Jesse Rothstein, Rob Sampson, Burt Singer, Finn Tarp, Alessandro Tarozzi, Chris Udry, Gerard van den Berg, Eric Verhoogen, Susan Watkins, Frank Wolak, and John Worrall. I acknowledge a particular intellectual debt to Nancy Cartwright, who has discussed these issues patiently with 


\section{Introduction}

$\mathrm{T}$ he effectiveness of development assistance is a topic of great public interest. Much of the public debate among noneconomists takes it for granted that, if the funds were made available, poverty would be eliminated (Thomas Pogge 2005; Peter Singer 2004) and at least some economists agree (Jeffrey D. Sachs 2005, 2008). Others, most notably William Easterly (2006, 2009), are deeply skeptical, a position that has been forcefully argued at least since P. T. Bauer (1971, 1981). Few academic economists or political scientists agree with Sachs's views, but there is a wide range of intermediate positions, well assembled by Easterly (2008). The debate runs the gamut from the macrocan foreign assistance raise growth rates and eliminate poverty? - to the micro-what sorts of projects are likely to be effective?should aid focus on electricity and roads, or on the provision of schools and clinics or vaccination campaigns? Here I shall be concerned with both the macro and micro kinds of assistance. I shall have very little to say about what actually works and what does not-but it is clear from the literature that we do not know. Instead, my main concern is with how we should go about finding out whether and how assistance works and with methods for gathering evidence and learning from it in a scientific way that has some hope of leading to the progressive accumulation of useful knowledge about development. I am not an econometrician, but I believe

me for several years, whose own work on causality has greatly influenced me, and who pointed me toward other important work; to Jim Heckman, who has long thought deeply about these issues, and many of whose views are recounted here; and to the late David Freedman, who consistently and effectively fought against the (mis)use of technique as a substitute for substance and thought. None of which removes the need for the usual disclaimer, that the views expressed here are entirely my own. I acknowledge financial support from NIA through grant P01 AG0584214 to the National Bureau of Economic Research. that econometric methodology needs to be assessed, not only by methodologists, but by those who are concerned with the substance of the issue. Only they (we) are in a position to tell when something has gone wrong with the application of econometric methods, not because they are incorrect given their assumptions, but because their assumptions do not apply, or because they are incorrectly conceived for the problem at hand. Or at least that is my excuse for meddling in these matters.

Any analysis of the extent to which foreign aid has increased economic growth in recipient countries immediately confronts the familiar problem of simultaneous causality; the effect of aid on growth, if any, will be disguised by effects running in the opposite direction, from poor economic performance to compensatory or humanitarian aid. It is not obvious how to disentangle these effects, and some have argued that the question is unanswerable and that econometric studies of it should be abandoned. Certainly, the econometric studies that use international evidence to examine aid effectiveness currently have low professional status. Yet it cannot be right to give up on the issue. There is no general or public understanding that nothing can be said, and to give up the econometric analysis is simply to abandon precise statements for loose and unconstrained histories of episodes selected to support the position of the speaker.

The analysis of aid effectiveness typically uses cross-country growth regressions with the simultaneity between aid and growth dealt with using instrumental variable methods. I shall argue in the next section that there has been a good deal of misunderstanding in the literature about the use of instrumental variables. Econometric analysis has changed its focus over the years, away from the analysis of models derived from theory toward much looser specifications that are statistical representations of program evaluation. With 
this shift, instrumental variables have moved from being solutions to a well-defined problem of inference to being devices that induce quasi-randomization. Old and new understandings of instruments coexist, leading to errors, misunderstandings, and confusion, as well as unfortunate and unnecessary rhetorical barriers between disciplines working on the same problems. These abuses of technique have contributed to a general skepticism about the ability of econometric analysis to answer these big questions.

A similar state of affairs exists in the microeconomic area, in the analysis of the effectiveness of individual programs and projects, such as the construction of infrastructuredams, roads, water supply, electricity —and in the delivery of services - education, health, or policing. There is frustration with aid organizations, particularly the World Bank, for allegedly failing to learn from its projects and to build up a systematic catalog of what works and what does not. In addition, some of the skepticism about macro econometrics extends to micro econometrics, so that there has been a movement away from such methods and toward randomized controlled trials. According to Esther Duflo, one of the leaders of the new movement in development, "Creating a culture in which rigorous randomized evaluations are promoted, encouraged, and financed has the potential to revolutionize social policy during the 21st century, just as randomized trials revolutionized medicine during the 20th," this from a 2004 Lancet editorial headed "The World Bank is finally embracing science."

In section 4 of this paper, I shall argue that, under ideal circumstances, randomized evaluations of projects are useful for obtaining a convincing estimate of the average effect of a program or project. The price for this success is a focus that is too narrow and too local to tell us "what works" in development, to design policy, or to advance scientific knowledge about development processes.
Project evaluations, whether using randomized controlled trials or nonexperimental methods, are unlikely to disclose the secrets of development nor, unless they are guided by theory that is itself open to revision, are they likely to be the basis for a cumulative research program that might lead to a better understanding of development. This argument applies a fortiori to instrumental variables strategies that are aimed at generating quasi-experiments; the value of econometric methods cannot and should not be assessed by how closely they approximate randomized controlled trials. Following Nancy Cartwright (2007a, 2007b), I argue that evidence from randomized controlled trials can have no special priority. Randomization is not a gold standard because "there is no gold standard" Cartwright (2007a.) Randomized controlled trials cannot automatically trump other evidence, they do not occupy any special place in some hierarchy of evidence, nor does it make sense to refer to them as "hard" while other methods are "soft." These rhetorical devices are just that; metaphor is not argument, nor does endless repetition make it so.

More positively, I shall argue that the analysis of projects needs to be refocused toward the investigation of potentially generalizable mechanisms that explain why and in what contexts projects can be expected to work. The best of the experimental work in development economics already does so because its practitioners are too talented to be bound by their own methodological prescriptions. Yet there would be much to be said for doing so more openly. I concur with Ray Pawson and Nick Tilley (1997), who argue that thirty years of project evaluation in sociology, education, and criminology was largely unsuccessful because it focused on whether projects worked instead of on why they worked. In economics, warnings along the same lines have been repeatedly given by James J. Heckman (see particularly 
Heckman 1992 and Heckman and Jeffrey A. Smith 1995), and much of what I have to say is a recapitulation of his arguments.

The paper is organized as follows. Section 2 lays out some econometric preliminaries concerning instrumental variables and the vexed question of exogeneity. Section 3 is about aid and growth. Section 4 is about randomized controlled trials. Section 5 is about using empirical evidence and where we should go now.

\section{Instruments, Identification, and the Meaning of Exogeneity}

It is useful to begin with a simple and familiar econometric model that I can use to illustrate the differences between different flavors of econometric practice-this has nothing to do with economic development but it is simple and easy to contrast with the development practice that I wish to discuss. In contrast to the models that I will discuss later, I think of this as a model in the spirit of the Cowles Foundation. It is the simplest possible Keynesian macroeconomic model of national income determination taken from once-standard econometrics textbooks. There are two equations that together comprise a complete macroeconomic system. The first equation is a consumption function in which aggregate consumption is a linear function of aggregate national income, while the second is the national income accounting identity that says that income is the sum of consumption and investment. I write the system in standard notation as

$$
\begin{gathered}
C=\alpha+\beta Y+u, \\
Y \equiv C+I .
\end{gathered}
$$

According to (1), consumers choose the level of aggregate consumption with reference to their income, while in (2) investment is set by the "animal spirits" of entrepreneurs in some way that is outside of the model. No modern macroeconomist would take this model seriously, though the simple consumption function is an ancestor of more satisfactory and complete modern formulations; in particular, we can think of it (or at least its descendents) as being derived from a coherent model of intertemporal choice. Similarly, modern versions would postulate some theory for what determines investment $I$-here it is simply taken as given and assumed to be orthogonal to the consumption disturbance $u$.

In this model, consumption and income are simultaneously determined so that, in particular, a stochastic realization of $u-$ consumers displaying animal spirits of their own-will affect not only $C$ but also $Y$ through equation (2), so that there is a positive correlation between $u$ and $Y$. As a result, ordinary least squares (OLS) estimation of (1) will lead to upwardly biased and inconsistent estimates of the parameter $\beta$.

This simultaneity problem can be dealt with in a number of ways. One is to solve (1) and (2) to get the reduced form equations

$$
C=\frac{\alpha}{1-\beta}+\frac{\beta}{1-\beta} I+\frac{u}{1-\beta}
$$

$$
Y=\frac{\alpha}{1-\beta}+\frac{I}{1-\beta}+\frac{u}{1-\beta} .
$$

Both of these equations can be consistently estimated by OLS, and it is easy to show that the same estimates of $\alpha$ and $\beta$ will be obtained from either one. An alternative method of estimation is to focus on the consumption function (1) and to use our knowledge of (2) to note that investment can be used as an instrumental variable (IV) for income. In the IV regression, there is a "first stage" regression in which income is regressed on investment; this is identical to equation (4), which is part of the reduced 
form. In the second stage, consumption is regressed on the predicted value of income from (4). In this simple case, the IV estimate of $\beta$ is identical to the estimate from the reduced form. This simple model may not be a very good model-but it is a model, if only a primitive one.

I now leap forward sixty years and consider an apparently similar set up, again using an absurdly simple specification. The World Bank (let us imagine) is interested in whether to advise the government of China to build more railway stations as part of its poverty reduction strategy. The Bank economists write down an econometric model in which the poverty head count ratio in city $c$ is taken to be a linear function of an indicator $R$ of whether or not the city has a railway station,

$$
P_{c}=\gamma+\theta R_{c}+v_{c}
$$

where $\theta$ (I hesitate to call it a parameter) indicates the effect-presumably negativeof infrastructure (here a railway station) on poverty. While we cannot expect to get useful estimates of $\theta$ from OLS estimation of (5) railway stations may be built to serve more prosperous cities, they are rarely built in deserts where there are no people, or there may be "third factors" that influence both-this is seen as a "technical problem" for which there is a wide range of econometric treatments including, of course, instrumental variables.

We no longer have the reduced form of the previous model to guide us but, if we can find an instrument $Z$ that is correlated with whether a town has a railway station but uncorrelated with $v$, we can do the same calculations and obtain a consistent estimate. For the record, I write this equation

$$
R_{c}=\phi+\varphi Z_{c}+\eta_{c} .
$$

Good candidates for $Z$ might be indicators of whether the city has been designated by the Government of China as belonging to a special "infrastructure development area," or perhaps an earthquake that conveniently destroyed a selection of railway stations, or even the existence of river confluence near the city, since rivers were an early source of power, and railways served the power-based industries. I am making fun, but not much. And these instruments all have the real merit that there is some mechanism linking them to whether or not the town has a railway station, something that is not automatically guaranteed by the instrument being correlated with $R$ and uncorrelated with $v$ (see, for example, Peter C. Reiss and Frank A. Wolak 2007, pp. 4296-98).

My main argument is that the two econometric structures, in spite of their resemblance and the fact that IV techniques can be used for both, are in fact quite different. In particular, the IV procedures that work for the effect of national income on consumption are unlikely to give useful results for the effect of railway stations on poverty. To explain the differences, I begin with the language. In the original example, the reduced form is a fully specified system since it is derived from a notionally complete model of the determination of income. Consumption and income are treated symmetrically and appear as such in the reduced form equations (3) and (4). In contemporary examples, such as the railways, there is no complete theoretical system and there is no symmetry. Instead, we have a "main" equation (5), which used to be the "structural" equation (1). We also have a "first-stage" equation, which is the regression of railway stations on the instrument. The now rarely considered regression of the variable of interest on the instrument, here of poverty on earthquakes or on river confluences, is nowadays referred to as the reduced form, although it was originally one equation of a multiple equation reduced form-equation (6) is also part of the reduced form-within which it had no special significance. These language shifts 
sometimes cause confusion but they are not the most important differences between the two systems.

The crucial difference is that the relationship between railways and poverty is not a model at all, unlike the consumption model that embodied a(n admittedly crude) theory of income determination. While it is clearly possible that the construction of a railway station will reduce poverty, there are many possible mechanisms, some of which will work in one context and not in another. In consequence, $\theta$ is unlikely to be constant over different cities, nor can its variation be usefully thought of as random variation that is uncorrelated with anything else of interest. Instead, it is precisely the variation in $\theta$ that encapsulates the poverty reduction mechanisms that ought to be the main objects of our enquiry. Instead, the equation of interest-the socalled "main equation" (5) - is thought of as a representation of something more akin to an experiment or a biomedical trial in which some cities get "treated" with a station and some do not. The role of econometric analysis is not, as in the Cowles example, to estimate and investigate a casual model, but "to create an analogy, perhaps forced, between an observational study and an experiment" (David A. Freedman 2006, p. 691).

One immediate task is to recognize and somehow deal with the variation in $\theta$, which is typically referred to as the "heterogeneity problem" in the literature. The obvious way is to define a parameter of interest in a way that corresponds to something we want to know for policy evaluation-perhaps the average effect on poverty over some group of cities-and then devise an appropriate estimation strategy. However, this step is often skipped in practice, perhaps because of a mistaken belief that the "main equation" (5) is a structural equation in which $\theta$ is a constant, so that the analysis can go immediately to the choice of instrument $Z$, over which a great deal of imagination and ingenuity is often exercised. Such ingenuity is often needed because it is difficult simultaneously to satisfy both of the standard criteria required for an instrument, that it be correlated with $R_{c}$ and uncorrelated with $v_{c}$. However, if heterogeneity is indeed present, even satisfying the standard criteria is not sufficient to prevent the probability limit of the IV estimator depending on the choice of instrument (Heckman 1997). Without explicit prior consideration of the effect of the instrument choice on the parameter being estimated, such a procedure is effectively the opposite of standard statistical practice in which a parameter of interest is defined first, followed by an estimator that delivers that parameter. Instead, we have a procedure in which the choice of the instrument, which is guided by criteria designed for a situation in which there is no heterogeneity, is implicitly allowed to determine the parameter of interest. This goes beyond the old story of looking for an object where the light is strong enough to see; rather, we have at least some control over the light but choose to let it fall where it may and then proclaim that whatever it illuminates is what we were looking for all along.

Recent econometric analysis has given us a more precise characterization of what we can expect from such a method. In the railway example, where the instrument is the designation of a city as belonging to the "special infrastructure zone," the probability limit of the IV estimator is the average of poverty reduction effects over those cities who were induced to construct a railway station by being so designated. This average is known as the "local average treatment effect" (LATE) and its recovery by IV estimation requires a number of nontrivial conditions, including, for example, that no cities who would have constructed a railway station are perverse enough to be actually deterred from doing so by the positive designation (see Guido W. Imbens and Joshua D. Angrist 1994, who established the 
LATE theorem). The LATE may or may not be a parameter of interest to the World Bank or the Chinese government and, in general, there is no reason to suppose that it will be. For example, the parameter estimated will typically not be the average poverty reduction effect over the designated cities, nor will it be the average effect over all cities.

I find it hard to make any sense of the LATE. We are unlikely to learn much about the processes at work if we refuse to say anything about what determines $\theta$; heterogeneity is not a technical problem calling for an econometric solution but a reflection of the fact that we have not started on our proper business, which is trying to understand what is going on. Of course, if we are as skeptical of the ability of economic theory to deliver useful models as are many applied economists today, the ability to avoid modeling can be seen as an advantage, though it should not be a surprise when such an approach delivers answers that are hard to interpret. Note that my complaint is not with the "local" nature of the LATE — that property is shared by many estimation strategies and I will discuss later how we might overcome it. The issue here is rather the "average" and the lack of an ex ante characterization of the set over which the averaging is done. Angrist and JörnSteffen Pischke (2010) have recently claimed that the explosion of instrumental variables methods, including LATE estimation, has led to greater "credibility" in applied econometrics. I am not entirely certain what credibility means, but it is surely undermined if the parameter being estimated is not what we want to know. While in many cases what is estimated may be close to, or may contain information about, the parameter of interest, that this is actually so requires demonstration and is not true in general (see Heckman and Sergio Urzua 2009, who analyze cases where the LATE is an uninteresting and potentially misleading assemblage of parts of the underlying structure).
There is a related issue that bedevils a good deal of contemporary applied work, which is the understanding of exogeneity, a word that I have so far avoided. Suppose, for the moment, that the effect of railway stations on poverty is the same in all cities and we are looking for an instrument, which is required to be exogenous in order to consistently estimate $\theta$. According to MerriamWebster's dictionary, "exogenous" means "caused by factors or an agent from outside the organism or system," and this common usage is often employed in applied work. However, the consistency of IV estimation requires that the instrument be orthogonal to the error term $v$ in the equation of interest, which is not implied by the MerriamWebster definition (see Edward E. Leamer 1985, p. 260). Jeffrey M. Wooldridge (2002, p. 50) warns his readers that "you should not rely too much on the meaning of 'endogenous' from other branches of economics" and goes on to note that "the usage in econometrics, while related to traditional definitions, is used broadly to describe any situation where an explanatory variable is correlated with the disturbance." Heckman (2000) suggests using the term "external" (which he traces back to Wright and Frisch in the 1930s) for the Merriam-Webster definition, for variables whose values are not set or caused by the variables in the model and keeping "exogenous" for the orthogonality condition that is required for consistent estimation in this instrumental variable context. The terms are hardly standard, but I adopt them here because I need to make the distinction. The main issue, however, is not the terminology but that the two concepts be kept distinct so that we can see when the argument being offered is a justification for externality when what is required is a justification for exogeneity. An instrument that is external, but not exogeneous, will not yield consistent estimates of the parameter of interest, even when the parameter of interest is a constant. 
An alternative approach is to keep the Miriam-Webster (or "other branches of economics") definition for exogenous and to require that, in addition to being exogenous, an instrument satisfy the "exclusion restrictions" of being uncorrelated with the disturbance. I have no objection to this usage, though the need to defend these additional restrictions is not always appreciated in practice. Yet exogeneity in this sense has no consequences for the consistency of econometric estimators and so is effectively meaningless.

Failure to separate externality and exogeneity_or to build a case for the validity of the exclusion restrictions-has caused, and continues to cause, endless confusion in the applied development (and other) literatures. Natural or geographic variables-distance from the equator (as an instrument for per capita GDP in explaining religiosity, Rachel M. McCleary and Robert J. Barro 2006), rivers (as an instrument for the number of school districts in explaining educational outcomes, Caroline M. Hoxby 2000), land gradient (as an instrument for dam construction in explaining poverty, Duflo and Rohini Pande 2007), or rainfall (as an instrument for economic growth in explaining civil war, Edward Miguel, Shanker Satyanath, and Ernest Sergenti 2004 and the examples could be multiplied ad infinitum) — are not affected by the variables being explained, and are clearly external. So are historical variablesthe mortality of colonial settlers is not influenced by current institutional arrangements in ex-colonial countries (Daron Acemoglu, Simon Johnson, and James A. Robinson 2001) nor does the country's growth rate today influence the identity of their past colonizers (Barro 1998). Whether any of these instruments is exogenous (or satisfies the exclusion restrictions) depends on the specification of the equation of interest, and is not guaranteed by its externality. And because exogeneity is an identifying assumption that must be made prior to analysis of the data, empirical tests cannot settle the question. This does not prevent many attempts in the literature, often by misinterpreting a satisfactory overidentification test as evidence for valid identification. Such tests can tell us whether estimates change when we select different subsets from a set of possible instruments. While the test is clearly useful and informative, acceptance is consistent with all of the instruments being invalid, while failure is consistent with a subset being correct. Passing an overidentification test does not validate instrumentation.

In my running example, earthquakes and rivers are external to the system and are neither caused by poverty nor by the construction of railway stations, and the designation as an infrastructure zone may also be determined by factors independent of poverty or railways. But even earthquakes (or rivers) are not exogenous if they have an effect on poverty other than through their destruction (or encouragement) of railway stations, as will almost always be the case. The absence of simultaneity does not guarantee exogeneityexogeneity requires the absence of simultaneity but is not implied by it. Even random numbers - the ultimate external variablesmay be endogenous, at least in the presence of heterogeneous effects if agents choose to accept or reject their assignment in a way that is correlated with the heterogeneity. Again, the example comes from Heckman's (1997) discussion of Angrist's (1990) famous use of draft lottery numbers as an instrumental variable in his analysis of the subsequent earnings of Vietnam veterans.

I can illustrate Heckman's argument using the Chinese railways example with the zone designation as instrument. Rewrite the equation of interest, (5), as

$$
\begin{aligned}
P_{c} & =\gamma+\bar{\theta} R_{c}+w_{c} \\
& =\gamma+\bar{\theta} R_{c}+\left\{v_{c}+(\theta-\bar{\theta}) R_{c}\right\},
\end{aligned}
$$


where $w_{c}$ is defined by the term in curly brackets, and $\bar{\theta}$ is the mean of $\theta$ over the cities that get the station so that the compound error term $w$ has mean zero. Suppose the designation as an infrastructure zone is $D_{c}$, which takes values 1 or 0 , and that the Chinese bureaucracy, persuaded by young development economists, decides to randomize and designates cities by flipping a yuan. For consistent estimation of $\bar{\theta}$, we want the covariance of the instrument with the error to be zero. The covariance is

$$
\begin{aligned}
E\left(D_{c} w_{c}\right)= & E[(\theta-\bar{\theta}) R D] \\
= & E[(\theta-\bar{\theta}) \mid D=1, R=1] \\
& \times P(D=1, R=1),
\end{aligned}
$$

which will be zero if either $(a)$ the average effect of building a railway station on poverty among the cities induced to build one by the designation is the same as the average effect among those who would have built one anyway, or (b) no city not designated builds a railway station. If $(b)$ is not guaranteed by fiat, we cannot suppose that it will otherwise hold, and we might reasonably hope that among the cities who build railway stations, those induced to do so by the designation are those where there is the largest effect on poverty, which violates $(a)$. In the example of the Vietnam veterans, the instrument (the draft lottery number) fails to be exogenous because the error term in the earnings equation depends on each individual's rate of return to schooling, and whether or not each potential draftee accepted their assignment-their veteran's status-depends on that rate of return. This failure of exogeneity is referred to by Richard Blundell and Monica Costa Dias (2009) as selection on idiosyncratic gain and it adds to any bias caused by any failure of the instrument to be orthogonal to $\nu_{c}$, ruled out here by the randomness of the instrument.

The general lesson is once again the ultimate futility of trying to avoid thinking about how and why things work-if we do not do so, we are left with undifferentiated heterogeneity that is likely to prevent consistent estimation of any parameter of interest. One appropriate response is to specify exactly how cities respond to their designation, an approach that leads to Heckman's local instrumental variable methods (Heckman and Edward Vytlacil 1999, 2007; Heckman, Urzua, and Vytlacil 2006). In a similar vein, David Card (1999) reviews estimates of the rate of return to schooling and explores how the choice of instruments leads to estimates that are averages over different subgroups of the population so that, by thinking about the implicit selection, evidence from different studies can be usefully summarized and compared. Similar questions are pursued in Gerard van den Berg (2008).

\section{Instruments of Development}

The question of whether aid has helped economies grow faster is typically asked within the framework of standard growth regressions. These regressions use data for many countries over a period of years, usually from the Penn World Table, the current version of which provides data on real per capita GDP and its components in purchasing power dollars for more than 150 countries as far back as 1950. The model to be estimated has the rate of growth of per capita GDP as the dependent variable, while the explanatory variables include the lagged value of GDP per capita, the share of investment in GDP, and measures of the educational level of the population (see, for example, Barro and Xavier Sala-i-Martin 1995, chapter 12, for an overview). Other variables are often added, and my main concern here is with one of these, external assistance (aid) as a 
fraction of GDP. A typical specification can be written

$$
\begin{aligned}
\Delta \ln Y_{c t+1}= & \beta_{0}+\beta_{1} \ln Y_{c t} \\
& +\beta_{2} \frac{I_{c t}}{Y_{c t}}+\beta_{3} H_{c t}+\beta_{4} Z_{c t} \\
& +\theta A_{c t}+u_{c t}
\end{aligned}
$$

where $Y$ is per capita GDP, $I$ is investment, $H$ is a measure of human capital or education, and $A$ is the variable of interest, aid as a share of GDP. $Z$ stands for whatever other variables are included. The index $c$ is for country and $t$ for time. Growth is rarely measured on a year to year basis - the data in the Penn World Table are not suitable for annual analysis - so that growth may be measured over ten, twenty, or forty year intervals. With around forty years of data, there are four, two, or one observation for each country.

An immediate question is whether the growth equation (9) is a model-based Cowlestype equation, as in my national income example, or whether it is more akin to the atheoretical analysis in my invented Chinese railway example. There are elements of both here. If we ignore the $Z$ and $A$ variables in (9), the model can be thought of as a Solow growth model, extended to add human capital to physical capital (see again Barro and Salai-Martin, who derive their empirical specifications from the theory, and also N. Gregory Mankiw, David Romer, and David N. Weil 1992, who extended the Solow model to include education). However, the addition of the other variables, including aid, is typically less well justified. In some cases, for example under the assumption that all aid is invested, it is possible to calculate what effect we might expect aid to have (see Raghuram G. Rajan and Arvind Subramanian 2008). If we follow this route, (9) would not be useful-because aid is already included-and we should instead investigate whether aid is indeed invested, and then infer the effectiveness of aid from the effectiveness of investment. Even so, it presumably matters what kind of investment is promoted by aid, and aid for roads, for dams, for vaccination programs, or for humanitarian purposes after an earthquake are likely to have different effects on subsequent growth. More broadly, one of the main issues of contention in the debate is what aid actually does. Just to list a few of the possibilities, does aid increase investment, does aid crowd out domestic investment, is aid stolen, does aid create rent-seeking, or does aid undermine the institutions that are required for growth? Once all of these possibilities are admitted, it is clear that the analysis of (9) is not a Cowles model at all, but is seen as analogous to a biomedical experiment in which different countries are "dosed" with different amounts of aid, and we are trying to measure the average response. As in the Chinese railways case, a regression such as (9) will not give us what we want because the doses of aid are not randomly administered to different countries, so our first task is to find an instrumental variable that will generate quasi-randomness.

The most obvious problem with a regression of aid on growth is the simultaneous feedback from growth to aid that is generated by humanitarian responses to economic collapse or to natural or man-made disasters that engender economic collapse. More generally, aid flows from rich countries to poor countries, and poor countries, almost by definition, are those with poor records of economic growth. This feedback, from low growth to high aid, will obscure, nullify, or reverse any positive effects of aid. Most of the literature attempts to eliminate this feedback by using one or more instrumental variables and, although they would not express it in these terms, the aim of the instrumentation is to a restore a situation in which the pure effect of aid on growth can be observed as if in a randomized situation. How close we get to this ideal depends, of course, on the choice of instrument. 
Although there is some variation across studies, there is a standard set of instruments, originally proposed by Peter Boone (1996), which includes the log of population size and various country dummies, for example, a dummy for Egypt or for francophone West Africa. One or both of these instruments are used in almost all the papers in a large subsequent literature, including Craig Burnside and David Dollar (2000), Henrik Hansen and Finn Tarp (2000, 2001), Carl-Johan Dalgaard and Hansen (2001), Patrick Guillaumont and Lisa Chauvet (2001), Robert Lensink and Howard White (2001), Easterly, Ross Levine, and David Roodman (2004), Dalgaard, Hansen, and Tarp (2004), Michael Clemens, Steven Radelet, and Rikhil Bhavnani (2004), Rajan and Subramanian (2008), and Roodman (2007). The rationale for population size is that larger countries get less aid per capita because the aid agencies allocate aid on a country basis, with less than full allowance for population size. The rationale for what I shall refer to as the "Egypt instrument" is that Egypt gets a great deal of American aid as part of the Camp David accords in which it agreed to a partial rapprochement with Israel. The same argument applies to the francophone countries, which receive additional aid from France because of their French colonial legacy. By comparing these countries with countries not so favored or by comparing populous with less populous countries, we can observe a kind of variation in the share of aid in GDP that is unaffected by the negative feedback from poor growth to compensatory aid. In effect, we are using the variation across populations of different sizes as a natural experiment to reveal the effects of aid.

If we examine the effects of aid on growth without any allowance for reverse causality, for example by estimating equation (9) by OLS, the estimated effect is typically negative. For example, Rajan and Subramanian (2008), in one of the most careful recent studies, find that an increase in aid by one percent of GDP comes with a reduction in the growth rate of one tenth of a percentage point a year. Easterly (2006) provides many other (sometimes spectacular) examples of negative associations between aid and growth. When instrumental variables are used to eliminate the reverse causality, Rajan and Subramanian find a weak or zero effect of aid and contrast that finding with the robust positive effects of investment on growth in specifications like (9). I should note that, although Rajan and Subramanian's study is an excellent one, it is certainly not without its problems and, as the authors note, there are many difficult econometric problems over and above the choice of instruments, including how to estimate dynamic models with country fixed effects on limited data, the choice of countries and sample period, the type of aid that needs to be considered, and so on. Indeed, it is those other issues that are the focus of most of the literature cited above. The substance of this debate is far from over.

My main concern here is with the use of the instruments, what they tell us, and what they might tell us. The first point is that neither the "Egypt" (or colonial heritage) nor the population instrument are plausibly exogenous; both are external—Camp David is not part of the model, nor was it caused by Egypt's economic growth, and similarly for population size-but exogeneity would require that neither "Egypt" nor population size have any influence on economic growth except through the effects on aid flows, which makes no sense at all. We also need to recognize the heterogeneity in the aid responses and try to think about how the different instruments are implicitly choosing different averages, involving different weightings or subgroups of countries. Or we could stop right here, conclude that there are no valid instruments, and that the aid to growth question is not answerable in this way. I shall argue otherwise, but I should also note that similar challenges over the validity 
of instruments have become routine in applied econometrics, leading to widespread skepticism by some, while others press on undaunted in an ever more creative search for exogeneity.

Yet consideration of the instruments is not without value, especially if we move away from instrumental variable estimation, with the use of instruments seen as technical, not substantive, and think about the reduced form which contains substantive information about the relationship between growth and the instruments. For the case of population size, we find that, conditional on the other variables, population size is unrelated to growth, which is one of the reasons that the IV estimates of the effects of aid are small or zero. This (partial) regression coefficient is a much simpler object than is the instrumental variable estimate; under standard assumptions, it tells us how much faster large countries grow than small countries, once the standard effects of the augmented Solow model have been taken into account. Does this tell us anything about the effectiveness of aid? Not directly, though it is surely useful to know that, while larger countries receive less per capita aid in relation to per capita income, they grow just as fast as countries that have received more, once we take into account the amount that they invest, their levels of education, and their starting level of GDP. But we would hardly conclude from this fact alone that aid does not increase growth. Perhaps aid works less well in small countries, or perhaps there is an offsetting positive effect of population size on economic growth. Both are possible and both are worth further investigation. More generally, such arguments are susceptible to fruitful discussions, not only among economists, but also with other social scientists and historians who study these questions, something that is typically difficult with instrumental variable methods. Economists' claims to methodological superiority based on instrumental variables ring particularly hollow when it is economists themselves who are so often misled. My argument is that, for both economists and noneconomists, the direct consideration of the reduced form is likely to generate productive lines of enquiry.

The case of the "Egypt" instrument is somewhat different. Once again the reduced form is useful (Egypt doesn't grow particularly fast in spite of all the aid it gets in consequence of Camp David), though mostly for making it immediately clear that the comparison of Egypt versus non-Egypt, or francophone versus nonfrancophone, is not a useful way of assessing the effectiveness of aid on growth. There is no reason to suppose that "being Egypt" has no effect on its growth other than through aid from the United States. Yet almost every paper in this literature unquestioningly uses the Egypt dummy as an instrument. Similar instruments based on colonial heritage face exactly the same problem; colonial heritage certainly affects aid, and colonial heritage is not influenced by current growth performance, but different colonists behaved differently and left different legacies of institutions and infrastructure, all of which have their own persistent effect on growth today.

The use of population size, an Egypt dummy, or colonial heritage variables as instruments in the analysis of aid effectiveness cannot be justified. These instruments are external, not exogenous, or if we use the Webster definition of exogeneity, they clearly fail the exclusion restrictions. Yet they continue in almost universal use in the aideffectiveness literature, and are endorsed for this purpose by the leading exponents of IV methods (Angrist and Pischke 2010).

I conclude this section with an example that helps bridge the gap between analyses of the macro and analyses of the micro effects of aid. Many microeconomists agree that instrumentation in cross-country regressions is unlikely to be useful, while claiming 
that microeconomic analysis is capable of doing better. We may not be able to answer ill-posed questions about the macroeconomic effects of foreign assistance, but we can surely do better on specific projects and programs. Abhijit Vinayak Banerjee and Ruimin He (2008) have provided a list of the sort of studies that they like and that they believe should be replicated more widely. One of these, also endorsed by Duflo (2004), is a famous paper by Angrist and Victor Lavy (1999) on whether schoolchildren do better in smaller classes, a position frequently endorsed by parents and by teacher's unions but not always supported by empirical work. The question is an important one for development assistance because smaller class sizes cost more and are a potential use for foreign aid. Angrist and Lavy's paper uses a natural experiment, not a real one, and relies on IV estimation, so it provides a bridge between the relatively weak natural experiments in this section, and the actual randomized controlled trials in the next.

Angrist and Lavy's study is about the allocation of children enrolled in a school into classes. Many countries set their class sizes to conform to some version of Maimonides' rule, which sets a maximum class size, beyond which additional teachers must be found. In Israel, the maximum class size is set at 40. If there are less than 40 children enrolled, they will all be in the same class. If there are 41 , there will be two classes, one of 20 , and one of 21 . If there are 81 or more children, the first two classes will be full, and more must be set up. Angrist and Lavy's figure 1 plots actual class size and Maimonides' rule class size against the number of children enrolled; this graph starts off running along the 45-degree line, and then falls discontinuously to 20 when enrollment is 40 , increasing with slope of 0.5 to 80 , falling to 27.7 ( 80 divided by 3 ) at 80 , rising again with a slope of 0.25 , and so on. They show that actual class sizes, while not exactly conforming to the rule, are strongly influenced by it and exhibit the same saw tooth pattern. They then plot test scores against enrollment, and show that they display the opposite pattern, rising at each of the discontinuities where class size abruptly falls. This is a natural experiment, with Maimonides' rule inducing quasiexperimental variation, and generating a predicted class size for each level of enrollment which serves as an instrumental variable in a regression of test scores on class size. These IV estimates, unlike the OLS estimates, show that children in smaller classes do better.

Angrist and Lavy's paper, the creativity of its method, and the clarity of its result has set the standard for micro empirical work since it was published, and it has had a far-reaching effect on subsequent empirical work in labor and development economics. Yet there is a problem, which has become apparent over time. Note first the heterogeneity; it is improbable that the effect of lower class size is the same for all children so that, under the assumptions of the LATE theorem, the IV estimate recovers a weighted average of the effects for those children who are shifted by Maimonides' rule from a larger to a smaller class. Those children might not be the same as other children, which makes it hard to know how useful the numbers might be in other contexts, for example when all children are put in smaller class sizes. The underlying reasons for this heterogeneity are not addressed in this quasi-experimental approach. To be sure of what is happening here, we need to know more about how different children finish up in different classes, which raises the possibility that the variation across the discontinuities may not be orthogonal to other factors that affect test scores.

A recent paper by Miguel Urquiola and Eric Verhoogen (2009) explores how it is that children are allocated to different class sizes in a related, but different, situation in Chile where a version of Maimonides' rule is 
in place. Urquiola and Verhoogen note that parents care a great deal about whether their children are in the 40 child class or the 20 child class, and for the private schools they study, they construct a model in which there is sorting across the boundary, so that the children in the smaller classes have richer, more educated parents than the children in the larger classes. Their data match such a model, so that at least some of the differences in test scores across class size come from differences in the children that would be present whatever the class size. This paper is an elegant example of why it is so dangerous to make inferences from natural experiments without understanding the mechanisms at work. It also strongly suggests that the question of the effects of class size on student performance is not well-defined without a description of the environment in which class size is being changed (see also Christopher A. Sims 2010).

Another good example comes to me in private correspondence from Branko Milanovic, who was a child in Belgrade in a school only half of whose teachers could teach in English, and who was randomly assigned to a class taught in Russian. He remembers losing friends whose parents (correctly) perceived the superior value of an English education, and were insufficiently dedicated socialists to accept their assignment. The two language groups of children remaining in the school, although "randomly" assigned, are far from identical, and IV estimates using the randomization could overstate the superiority of the English medium education.

More generally, these are examples where an instrument induces actual or quasi-random assignment, here of children into different classes, but where the assignment can be undone, at least partially, by the actions of the subjects. If children - or their parentscare about whether they are in small or large classes, or in Russian or English classes, some will take evasive action-by protesting to authorities, finding a different school, or even moving - and these actions will generally differ by rich and poor children, by children with more or less educated parents, or by any factor that affects the cost to the child of being in a larger class. The behavioral response to the quasi-randomization (or indeed randomization) means that the groups being compared are not identical to start with (see also Justin McCrary 2008 and David S. Lee and Thomas Lemieux 2009 for further discussion and for methods of detection when this is happening).

In preparation for the next section, I note that the problem here is not the fact that we have a quasi-experiment rather than a real experiment, so that there was no actual randomization. If children had been randomized into class size, as in the Belgrade example, the problems would have been the same unless there had been some mechanism for forcing the children (and their parents) to accept the assignment.

\section{Randomization in the Tropics}

Skepticism about econometrics, doubts about the usefulness of structural models in economics, and the endless wrangling over identification and instrumental variables has led to a search for alternative ways of learning about development. There has also been frustration with the World Bank's apparent failure to learn from its own projects and its inability to provide a convincing argument that its past activities have enhanced economic growth and poverty reduction. Past development practice is seen as a succession of fads, with one supposed magic bullet replacing another-from planning to infrastructure to human capital to structural adjustment to health and social capital to the environment and back to infrastructure-a process that seems not to be guided by progressive learning. For many economists, and particularly for the 
group at the Poverty Action Lab at MIT, the solution has been to move toward randomized controlled trials of projects, programs, and policies. RCTs are seen as generating gold standard evidence that is superior to econometric evidence and that is immune to the methodological criticisms that are typically directed at econometric analyses. Another aim of the program is to persuade the World Bank to replace its current evaluation methods with RCTs; Duflo (2004) argues that randomized trials of projects would generate knowledge that could be used elsewhere, an international public good. Banerjee (2007b, chapter 1) accuses the Bank of "lazy thinking," of a "resistance to knowledge," and notes that its recommendations for poverty reduction and empowerment show a striking "lack of distinction made between strategies founded on the hard evidence provided by randomized trials or natural experiments and the rest." In all this there is a close parallel with the evidence-based movement in medicine that preceded it, and the successes of RCTs in medicine are frequently cited. Yet the parallels are almost entirely rhetorical, and there is little or no reference to the dissenting literature, as surveyed for example in John Worrall (2007) who documents the rise and fall in medicine of the rhetoric used by Banerjee. Nor is there any recognition of the many problems of medical RCTs, some of which I shall discuss as I go.

The movement in favor of RCTs is currently very successful. The World Bank is now conducting substantial numbers of randomized trials, and the methodology is sometimes explicitly requested by governments, who supply the World Bank with funds for this purpose (see World Bank 2008 for details of the Spanish Trust Fund for Impact Evaluation). There is a new International Initiative for Impact Evaluation which "seeks to improve the lives of poor people in low- and middleincome countries by providing, and summa- rizing, evidence of what works, when, why and for how much," (International Initiative for Impact Evaluation 2008), although not exclusively by randomized controlled trials. The Poverty Action Lab lists dozens of completed and ongoing projects in a large number of countries, many of which are project evaluations. Many development economists would join many physicians in subscribing to the jingoist view proclaimed by the editors of the British Medical Journal (quoted by Worrall 2007, p. 996) which noted that "Britain has given the world Shakespeare, Newtonian physics, the theory of evolution, parliamentary democracy-and the randomized trial."

\subsection{The Ideal RCT}

Under ideal conditions and when correctly executed, an RCT can estimate certain quantities of interest with minimal assumptions, thus absolving RCTs of one complaint against econometric methods-that they rest on often implausible economic models. It is useful to lay out briefly the (standard) framework for these results, originally due to Jerzy Neyman in the 1920s, currently often referred to as the Holland-Rubin framework or the Rubin causal model (see Freedman 2006 for a discussion of the history). According to this, each member of the population under study, labeled $i$, has two possible values associated with it, $Y_{0 i}$ and $Y_{1 i}$, which are the outcomes that $i$ would display if it did not get the treatment, $T_{i}=0$, and if it did get the treatment, $T_{i}=1$. Since each $i$ is either in the treatment group or in the control group, we observe one of $Y_{0 i}$ and $Y_{1 i}$ but not both. We would like to know something about the distribution over $i$ of the effects of the treatment, $Y_{i 1}-Y_{i 0}$, in particular its mean $\bar{Y}_{1}-\bar{Y}_{0}$. In a sense, the most surprising thing about this set-up is that we can say anything at all without further assumptions or without any modeling. But that is the magic that is wrought by the randomization. 
What we can observe in the data is the difference between the average outcome in the treatments and the average outcome in the controls, or $E\left(Y_{i} \mid T_{i}=1\right)-E\left(Y_{i} \mid T_{i}=0\right)$. This difference can be broken up into two terms

$$
\begin{aligned}
& E\left(Y_{i 1} \mid T_{i}=1\right)-E\left(Y_{i 0} \mid T_{i}=0\right) \\
& =\left[E\left(Y_{i 1} \mid T_{i}=1\right)-E\left(Y_{i 0} \mid T_{i}=1\right)\right] \\
& +\left[E\left(Y_{i 0} \mid T_{i}=1\right)-E\left(Y_{i 0} \mid T_{i}=0\right)\right] .
\end{aligned}
$$

Note that on the right hand side the second term in the first square bracket cancels out with the first term in the second square bracket. But the term in the second square bracket is zero by randomization; the nontreatment outcomes, like any other characteristic, are identical in expectation in the control and treatment groups. We can therefore write (10) as

$$
\begin{aligned}
& E\left(Y_{i 1} \mid T_{i}=1\right)-E\left(Y_{i 0} \mid T_{i}=0\right) \\
& =\left[E\left(Y_{i 1} \mid T_{i}=1\right)-E\left(Y_{i 0} \mid T_{i}=1\right)\right]
\end{aligned}
$$

so that the difference in the two observable outcomes is the difference between the average treated outcome and the average untreated outcome in the treatment group. The last term on the right hand side would be unobservable in the absence of randomization.

We are not quite done. What we would like is the average of the difference, rather than the difference of averages that is currently on the right-hand side of (11). But the expectation is a linear operator, so that the difference of the averages is identical to the average of the differences, so that we reach, finally

$$
\begin{aligned}
& E\left(Y_{i 1} \mid T_{i}=1\right)-E\left(Y_{i 0} \mid T_{i}=0\right) \\
& =\left[E\left(Y_{i 1}-Y_{i 0} \mid T_{i}=1\right)\right.
\end{aligned}
$$

The difference in means between the treatments and controls is an estimate of the average treatment effect among the treated, which, since the treatment and controls differ only by randomization, is an estimate of the average treatment effect for all. This standard but remarkable result depends both on randomization and on the linearity of expectations.

One immediate consequence of this derivation is a fact that is often quoted by critics of RCTs, but often ignored by practitioners, at least in economics: RCTs are informative about the mean of the treatment effects, $Y_{i 1}-Y_{i 0}$, but do not identify other features of the distribution. For example, the median of the difference is not the difference in medians, so an RCT is not, by itself, informative about the median treatment effect, something that could be of as much interest to policymakers as the mean treatment effect. It might also be useful to know the fraction of the population for which the treatment effect is positive, which once again is not identified from a trial. Put differently, the trial might reveal an average positive effect although nearly all of the population is hurt with a few receiving very large benefits, a situation that cannot be revealed by the RCT, although it might be disastrous if implemented. Indeed, Ravi Kanbur (2001) has argued that much of the disagreement about development policy is driven by differences of this kind.

Given the minimal assumptions that go into an RCT, it is not surprising that it cannot tell us everything that we would like to know. Heckman and Smith (1995) discuss these issues at greater length and also note that, in some circumstances, more can be learned. Essentially, the RCT gives us two marginal distributions from which we would like to infer a joint distribution; this is impossible, but the marginal distributions limit the joint distribution in ways that can be useful. For example, Charles F. Manski (1996) 
notes that a planner who is maximizing the expected value of a social welfare function needs only the two marginal distributions to check the usefulness of the treatment. Beyond that, if the probability distribution of outcomes among the treated stochastically dominates the distribution among the controls, we know that appropriately defined classes of social welfare functions will show an improvement without having to know what the social welfare function is. Not all relevant cases are covered by these examples; even if a drug saves lives on average, we need to know whether it is uniformly beneficial or kills some and saves more. To answer such questions, we will have to make assumptions beyond those required for an RCT; as usual, some questions can be answered with fewer assumptions than others.

In practice, researchers who conduct randomized controlled trials often do present results on statistics other than the mean. For example, the results can be used to run a regression of the form

$$
\begin{aligned}
Y_{i}= & \beta_{0}+\beta_{1} T_{i}+\sum_{j} \theta_{j} X_{i j} \\
& +\sum_{j} \phi_{j} X_{i j} \times T_{i}+u_{i},
\end{aligned}
$$

where $T$ is a binary variable that indicates treatment status, and the $X$ 's are various characteristics measured at baseline that are included in the regression both on their own (main effects) and as interactions with treatment status (see Suresh de Mel, David McKenzie, and Christopher Woodruff 2008 for an example of a field experiment with micro-enterprises in Sri Lanka). The estimated treatment effect now varies across the population, so that it is possible, for example, to estimate whether the average treatment effect is positive or negative for various subgroups of interest. These estimates depend on more assumptions than the trial itself, in particular on the validity of running a regression like (13), on which I shall have more to say below. One immediate charge against such a procedure is data mining. A sufficiently determined examination of any trial will eventually reveal some subgroup for which the treatment yielded a significant effect of some sort, and there is no general way of adjusting standard errors to protect against the possibility. A classic example from medicine comes from the ISIS- 2 trial of the use of aspirin after heart attacks (Richard Peto, Rory Collins, and Richard Gray 1995). A randomized trial established a beneficial effect with a significance level of better than $10^{-6}$, yet ex post analysis of the data showed that there was no significant effect for trial subjects whose astrological signs were Libra or Gemini. In drug trials, the FDA rules require that analytical plans be submitted prior to trials and drugs cannot be approved based on ex post data analysis. As noted by Robert J. Sampson (2008), one analysis of the recent Moving to Opportunity experiment has an appendix listing tests of many thousands of outcomes (Lisa Sanbonmatsu et al. 2006).

I am not arguing against posttrial subgroup analysis, only that, as is enshrined in the FDA rules, any special epistemic status (as in "gold standard," "hard," or "rigorous" evidence) possessed by RCTs does not extend to ex post subgroup analysis if only because there is no guarantee that a new RCT on post-experimentally defined subgroups will yield the same result. Such analyses do not share any special evidential status that might arguably be accorded to RCTs and must be assessed in exactly the same way as we would assess any nonexperimental or econometric study. These issues are wonderfully exposed by the subgroup analysis of drug effectiveness by Ralph I. Horwitz et al. (1996), criticized by Douglas G. Altman (1998), who refers to such studies as "a false trail," by Stephen Senn and Frank Harrell (1997), 
who call them "wisdom after the event," and by George Davey Smith and Matthias Egger (1998), who call them "incommunicable knowledge," drawing the response by Horwitz et al. (1997) that their critics have reached "the tunnel at the end of the light." While it is clearly absurd to discard data because we do not know how to analyze it with sufficient purity and while many important findings have come from posttrial analysis of experimental data, both in medicine and in economics, for example of the negative income tax experiments of the 1960s, the concern about data-mining remains real enough. In large-scale, expensive trials, a zero or very small result is unlikely to be welcomed, and there is likely to be considerable pressure to search for some subpopulation or some outcome that shows a more palatable result, if only to help justify the cost of the trial.

The mean treatment effect from an RCT may be of limited value for a physician or a policymaker contemplating specific patients or policies. A new drug might do better than a placebo in an RCT, yet a physician might be entirely correct in not prescribing it for a patient whose characteristics, according to the physician's theory of the disease, might lead her to suppose that the drug would be harmful. Similarly, if we are convinced that dams in India do not reduce poverty on average, as in Duflo and Pande's (2007) IV study, there is no implication about any specific dam, even one of the dams included in the study, yet it is always a specific dam that a policymaker has to approve. Their evidence certainly puts a higher burden of proof on those proposing a new dam, as would be the case for a physician prescribing in the face of an RCT, though the force of the evidence depends on the size of the mean effect and the extent of the heterogeneity in the responses. As was the case with the material discussed in sections 2 and 3, heterogeneity poses problems for the analysis of RCTs, just as it posed problems for nonexperimental methods that sought to approximate randomization. For this reason, in his Planning of Experiments, David R. Cox (1958, p. 15) begins his book with the assumption that the treatment effects are identical for all subjects. He notes that the RCT will still estimate the mean treatment effect with heterogeneity but argues that such estimates are "quite misleading," citing the example of two internally homogeneous subgroups with distinct average treatment effects, so that the RCT delivers an estimate that applies to no one. Cox's recommendation makes a good deal of sense when the experiment is being applied to the parameter of a well-specified model, but it could not be further away from most current practice in either medicine or economics.

One of the reasons why subgroup analysis is so hard to resist is that researchers, however much they may wish to escape the straitjacket of theory, inevitably have some mechanism in mind, and some of those mechanisms can be "tested" on the data from the trial. Such "testing," of course, does not satisfy the strict evidential standards that the RCT has been set up to satisfy and, if the investigation is constrained to satisfy those standards, no ex post speculation is permitted. Without a prior theory and within its own evidentiary standards, an RCT targeted at "finding out what works" is not informative about mechanisms, if only because there are always multiple mechanisms at work. For example, when two independent but identical RCTs in two cities in India find that children's scores improved less in Mumbai than in Vadodora, the authors state "this is likely related to the fact that over 80 percent of the children in Mumbai had already mastered the basic language skills the program was covering" (Duflo, Rachel Glennerster, and Michael Kremer 2008). It is not clear how "likely" is established here, and there is certainly no evidence that conforms to 
the "gold standard" that is seen as one of the central justifications for the RCTs. For the same reason, repeated successful replications of a "what works" experiment, i.e., one that is unrelated to some underlying or guiding mechanism, is both unlikely and unlikely to be persuasive. Learning about theory, or mechanisms, requires that the investigation be targeted toward that theory, toward why something works, not whether it works. Projects can rarely be replicated, though the mechanisms underlying success or failure will often be replicable and transportable. This means that, if the World Bank had indeed randomized all of its past projects, it is unlikely that the cumulated evidence would contain the key to economic development.

Cartwright (2007a) summarizes the benefits of RCTs relative to other forms of evidence. In the ideal case, "if the assumptions of the test are met, a positive result implies the appropriate causal conclusion," that the intervention "worked" and caused a positive outcome. She adds "the benefit that the conclusions follow deductively in the ideal case comes with great cost: narrowness of scope" (p. 11).

\subsection{Tropical RCTs in Practice}

How well do actual RCTs approximate the ideal? Are the assumptions generally met in practice? Is the narrowness of scope a price that brings real benefits or is the superiority of RCTs largely rhetorical? RCTs allow the investigator to induce variation that might not arise nonexperimentally, and this variation can reveal responses that could never have been found otherwise. Are these responses the relevant ones? As always, there is no substitute for examining each study in detail, and there is certainly nothing in the RCT methodology itself that grants immunity from problems of implementation. Yet there are some general points that are worth discussion.
The first is the seemingly obvious practical matter of how to compute the results of a trial. In theory, this is straightforward-we simply compare the mean outcome in the experimental group with the mean outcome in the control group and the difference is the causal effect of the intervention. This simplicity, compared with the often baroque complexity of econometric estimators, is seen as one of the great advantages of RCTs, both in generating convincing results and in explaining those results to policymakers and the lay public. Yet any difference is not useful without a standard error and the calculation of the standard error is rarely quite so straightforward. As Ronald A. Fisher (1935) emphasized from the very beginning, in his famous discussion of the tea lady, randomization plays two separate roles. The first is to guarantee that the probability law governing the selection of the control group is the same as the probability law governing the selection of the experimental group. The second is to provide a probability law that enables us to judge whether a difference between the two groups is significant. In his tea lady example, Fisher uses combinatoric analysis to calculate the exact probabilities of each possible outcome, but in practice this is rarely done.

Duflo, Glennerster, and Kremer (2008, p. 3921) (DGK) explicitly recommend what seems to have become the standard method in the development literature, which is to run a restricted version of the regression (13), including only the constant and the treatment dummy,

$$
Y_{i}=\beta_{0}+\beta_{1} T_{i}+u_{i} .
$$

As is easily shown, the OLS estimate of $\beta_{1}$ is simply the difference between the mean of the $Y_{i}$ in the experimental and control groups, which is exactly what we want. However, the standard error of $\beta_{1}$ from the OLS regression is not generally correct. One problem is that the variance among the 
experimentals may be different from the variance among the controls, and to assume that the experiment does not affect the variance is very much against the minimalist spirit of RCTs. If the regression (14) is run with the standard heteroskedasticity correction to the standard error, the result will be the same as the formula for the standard error of the difference between two means, but not otherwise except in the special case where there are equal numbers of experimental and controls, in which case it turns out that the correction makes no difference and the OLS standard error is correct. It is not clear in the experimental development literature whether the correction is routinely done in practice, and the handbook review by DGK makes no mention of it, although it provides a thoroughly useful review of many other aspects of standard errors.

Even with the correction for unequal variances, we are not quite done. The general problem of testing the significance of the differences between the means of two normal populations with different variances is known as the Fisher-Behrens problem. The test statistic computed by dividing the difference in means by its estimated standard error does not have the $t$-distribution when the variances are different in treatments and controls, and the significance of the estimated difference in means is likely to be overstated if no correction is made. If there are equal numbers of treatments and controls, the statistic will be approximately distributed as Student's $t$ but with degrees of freedom that can be as little as half the nominal degrees of freedom when one of the two variances is zero. In general, there is also no reason to suppose that the heterogeneity in the treatment effects is normal, which will further complicate inference in small samples.

Another standard practice, recommended by DGK, and which is also common in medical RCTs according to Freedman (2008), is to run the regression (14) with additional controls taken from the baseline data or equivalently (13) with the $X_{i}$ but without the interactions,

$$
Y_{i}=\beta_{0}+\beta_{1} T_{i}+\sum_{j} \theta_{j} X_{i j}+u_{i}
$$

The standard argument is that, if the randomization is done correctly, the $X_{i}$ will be orthogonal to the treatment variable $T_{i}$ so that their inclusion does not affect the estimate of $\beta_{1}$, which is the parameter of interest. However, by absorbing variance, as compared with (14), they will increase the precision of the estimate-this is not necessarily the case, but will often be true. DGK (p. 3924) give an example: "controlling for baseline test scores in evaluations of educational interventions greatly improves the precision of the estimates, which reduces the cost of these evaluations when a baseline test can be conducted."

There are two problems with this procedure. The first, which is noted by DGK, is that, as with posttrial subgroup analysis, there is a risk of data mining - trying different control variables until the experiment "works"- unless the control variables are specified in advance. Again, it is hard to tell whether or how often this dictum is observed. The second problem is analyzed by Freedman (2008), who notes that (15) is not a standard regression because of the heterogeneity of the responses. Write $\alpha_{i}$ for the (hypothetical) treatment response of unit $i$, so that, in line with the discussion in the previous subsection, $\alpha_{i}=Y_{i 1}-Y_{i 0}$, and we can write the identity

$$
\begin{aligned}
Y_{i} & =Y_{i 0}+\alpha_{i} T_{i} \\
& =\bar{Y}_{0}+\alpha_{i} T_{i}+\left(Y_{i 0}-\bar{Y}_{0}\right),
\end{aligned}
$$

which looks like the regression (15) with the $X$ 's and the error term capturing the variation in $Y_{i 0}$. The only difference is that 
the coefficient on the treatment term has an $i$ suffix because of the heterogeneity. If we define $\alpha=E\left(\alpha_{i} \mid T_{i}=1\right)$, the average treatment effect among the treated, as the parameter of interest, as in section 4.1, we can rewrite (16) as

$$
\begin{aligned}
Y_{i}= & \bar{Y}_{0}+\alpha T_{i}+\left(Y_{i 0}-\bar{Y}_{0}\right) \\
& +\left(\alpha_{i}-\alpha\right) T_{i} .
\end{aligned}
$$

Finally, and to illustrate, suppose that we model the variation in $Y_{i 0}$ as a linear function of an observable scalar $X_{i 0}$ and a residual $\eta_{i}$, we have

$$
\begin{aligned}
Y_{i}= & \beta_{0}+\alpha T_{i}+\theta\left(X_{i}-\bar{X}\right) \\
& +\left[\eta_{i}+\left(\alpha_{i}-\alpha\right) T_{i}\right]
\end{aligned}
$$

with $\beta_{0}=Y_{0}$, which is in the regression form (15) but allows us to see the links with the experimental quantities.

Equation (18) is analyzed in some detail by Freedman (2008). It is easily shown that $T_{i}$ is orthogonal to the compound error, but that this is not true of $X_{i}-\bar{X}$. However, the two right hand side variables are uncorrelated because of the randomization, so the OLS estimate of $\beta_{1}=\alpha$ is consistent. This is not true of $\theta$, though this may not be a problem if the aim is simply to reduce the sampling variance. A more serious issue is that the dependency between $T_{i}$ and the compound error term means that the OLS estimate of the average treatment effect $\alpha$ is biased, and in small samples this bias-which comes from the heterogeneity - may be substantial. Freedman notes that the leading term in the bias of the estimate of the OLS estimate of $\alpha$ is $\varphi / n$ where $n$ is the sample size and

$$
\varphi=-\lim \frac{1}{n} \sum_{i=1}^{n}\left(\alpha_{i}-\alpha\right) Z_{i}^{2}
$$

where $Z_{i}$ is the standardized ( $z$-score) version of $X_{i}$. Equation (19) shows that the bias comes from the heterogeneity, or more specifically, from a covariance between the heterogeneity in the treatment effects and the squares of the included covariates. With the sample sizes typically encountered in these experiments, which are often expensive to conduct, the bias can be substantial. One possible strategy here would be to compare the estimates of $\alpha$ with and without covariates; even ignoring pretest bias, it is not clear how to make such a comparison without a good estimate of the standard error. Alternatively, and as noted by Imbens (2009) in his commentary on this paper, it is possible to remove bias using a "saturated" regression model, for example by estimating (15) when the covariates are discrete and there is a complete set of interactions. This is equivalent to stratifying on each combination of values of the covariates, which diminishes any effect on reducing the standard errors and, unless the stratification is done ex ante, raises the usual concerns about data mining.

Of these and related issues in medical trials, Freedman (2008, p. 13) writes "Practitioners will doubtless be heard to object that they know all this perfectly well. Perhaps, but then why do they so often fit models without discussing assumptions?"

All of the issues so far can be dealt with, either by appropriately calculating standard errors or by refraining from the use of covariates, though this might involve drawing larger and more expensive samples. However, there are other practical problems that are harder to fix. One of these is that subjects may fail to accept assignment, so that people who are assigned to the experimental group may refuse, and controls may find a way of getting the treatment, and either may drop out of the experiment altogether. The classical remedy of double blinding, so that neither the subject nor the experimenter know which subject is in which group, is 
rarely feasible in social experiments-children know their class size-and is often not feasible in medical trials_-subjects may decipher the randomization, for example by asking a laboratory to check that their medicine is not a placebo. Heckman (1992) notes that, in contrast to people, "plots of grounds do not respond to anticipated treatments of fertilizer, nor can they excuse themselves from being treated." This makes the important point, further developed by Heckman in later work, that the deviations from assignment are almost certainly purposeful, at least in part. The people who struggle to escape their assignment will do so more vigorously the higher are the stakes, so that the deviations from assignment cannot be treated as random measurement error, but will compromise the results in fundamental ways.

Once again, there is a widely used technical fix, which is to run regressions like (15) or (18), with actual treatment status in place of the assigned treatment status $T_{i}$. This replacement will destroy the orthogonality between treatment and the error term, so that OLS estimation will no longer yield a consistent estimate of the average treatment effect among the treated. However, the assigned treatment status, which is known to the experimenter, is orthogonal to the error term and is correlated with the actual treatment status, and so can serve as an instrumental variable for the latter. But now we are back to the discussion of instrumental variables in section 2, and we are doing econometrics, not an ideal RCT. Under the assumption of no "defiers" - people who do the opposite of their assignment just because of the assignment (and it is not clear "just why are there no defiers" Freedman 2006) - the instrumental variable converges to the LATE. As before, it is unclear whether this is what we want, and there is no way to find out without modeling the behavior that is responsible for the heterogeneity of the response to assignment, as in the local instrumental variable approach developed by Heckman and his coauthors, Heckman and Vytlacil $(1999,2007)$. Alternatively, and as recommended by Freedman (2005, p. 4; 2006), it is always informative to make a simple unadjusted comparison of the average outcomes between treatments and controls according to the original assignment. This may also be enough if what we are concerned with is whether the treatment works or not, rather than with the size of the effect. In terms of instrumental variables, this is a recommendation to look at the reduced form, and again harks back to similar arguments in section 2 on aid effectiveness.

One common problem is that the people who agree to participate in the experiment (as either experimental or controls) are not themselves randomly drawn from the general population so that, even if the experiment itself if perfectly executed, the results are not transferable from the experimental to the parent population and will not be a reliable guide to policy in the parent population. In effect, the selection or omitted variable bias that is a potential problem in nonexperimental studies comes back in a different form and, without an analysis of the two biases, it is impossible to conclude which estimate is better-a biased nonexperimental analysis might do better than a randomized controlled trial if enrollment into the trial is nonrepresentative. In drug trials, ethical protocols typically require the principle of "equipoise" - that the physician, or at least physicians in general, believe that the patient has an equal chance of improvement with the experimental and control drug. Yet risk-averse patients will not accept such a gamble, so that there is selection into treatment, and the requirements of ethics and of representativity come into direct conflict. While this argument does not apply to all trials, there are many ways in which the experimental (experimentals plus controls) and parent populations can differ. 
There are also operational problems that afflict every actual experiment; these can be mitigated by careful planning-in RCTs compared with econometric analysis, most of the work is done before data collection, not after-but not always eliminated.

In this context, I turn to the flagship study of the new movement in development economics-Miguel and Kremer's (2004) study of intestinal worms in Kenya. This paper is repeatedly cited in DGK's manual and it is one of the exemplary studies cited by Duflo (2004) and by Banerjee and He (2008). It was written by two senior authors at leading research universities and published in the most prestigious technical journal in economics. It has also received a great deal of positive attention in the popular press (see, for example, David Leonhardt 2008) and has been influential in policy (see Poverty Action Lab 2007). In this study, a group of "seventyfive rural primary schools were phased into treatment in a randomized order," with the finding "that the program reduced school absenteeism by at least one quarter, with particularly large participation gains among the youngest children, making deworming a highly effective way to boost school participation among young children" (p. 159). The point of the RCT is less to show that deworming medicines are effective, but to show that school-based treatment is more effective than individual treatment because children infect one another. As befits a paper that aims to change method, there is emphasis on the virtues of randomization, and the word "random" or its derivatives appears some sixty times in the paper. However, the "randomization" in the study is actually an assignment of schools to three groups by their order in the alphabet as in Albert Infant School to group 1, Alfred Elementary to group 2, Bell's Academy to group 3, Christopher School to group 1 again, Dean's Infants to group 2 , and so on. Alphabetization, not randomization, was also used in the experiment on flip charts in schools by Paul Glewwe et al. (2004); this paper, like "Worms," is much cited as evidence in favor of the virtues of randomization.

Alphabetization may be a reasonable solution when randomization is impossible but we are then in the world of quasi- or natural experiments, not randomized experiments; in the latter, the balance of observable and unobservable factors in treatments and controls is guaranteed by design, at least in expectation, in the former, it has to be argued for each case, and the need for such argument is one of the main claims for the superiority of the randomized approach. As is true with all forms of quasi-randomization, alphabetization does not guarantee orthogonality with potential confounders, however plausible it may be in the Kenyan case. Resources are often allocated alphabetically because that is how many lists are presented (see, for example, Štěpán Jurajda and Daniel Münich 2009 for documentation of students being admitted into selective schools (partly) based on their position in the alphabet). If this were the case in Kenya, schools higher in the alphabet would be systematically different and this difference would be inherited in an attenuated form by the three groups. Indeed, this sort of contamination is described by Cox (1958, pp. 74-75) who explicitly warns against such designs. Of course, it is also possible that, in this case, the alphabetization causes no confounding with factors known or unknown. If so, there is still an issue with the calculation of standard errors. Without a probability law, we have no way of discovering whether the difference between treatments and controls could have arisen by chance. We might think of modeling the situation here by imagining that the assignment was equivalent to taking a random starting value and assigning every third school to treatment. If so, the fact that there are only three possible assignments of schools would have to be taken into account 
in calculating the standard errors, and nothing of this kind is reported. As it is, it is impossible to tell whether the experimental differences in these studies are or are not due to chance.

In this subsection, I have dwelt on practice not to critique particular studies or particular results; indeed it seems entirely plausible that deworming is a good idea and that the costs are low relative to other interventions. My main point here is different-that conducting good RCTs is exacting and often expensive, so that problems often arise that need to be dealt with by various econometric or statistical fixes. There is nothing wrong with such fixes in principle-though they often compromise the substance, as in the instrumental variable estimation to correct for failure of assignment-but their application takes us out of the world of ideal RCTs and back into the world of everyday econometrics and statistics. So that RCTs, although frequently useful, carry no special exemption from the routine statistical and substantive scrutiny that should be routinely applied to any empirical investigation.

Although it is well beyond my scope in this paper, I should note that RCTs in medicine-the gold standard to which development RCTs often compare themselves-also encounter practical difficulties, and their primacy is not without challenge. In particular, ethical (human subjects) questions surrounding RCTs in medicine have become severe enough to seriously limit what can be undertaken, and there is still no general agreement on a satisfactory ethical basis for RCTs. Selection into medical trials is not random from the population; in particular, patients are typically excluded if they suffer from conditions other than those targeted in the trial, so that researchers can examine effects without contamination from comorbidities. Yet many actual patients do have comorbidities-this is particularly true among the elderly-so drugs are frequently prescribed to those who were not represented in the original trials (Jerome Groopman 2009). In RCTs of some medical procedures, the hospitals chosen to participate are carefully selected, and favorable trial results may not be obtainable elsewhere (see David E. Wennberg et al. 1998 for an example in which actual mortality is many times higher than in the trials, sufficiently so as to reverse the desirability of the adoption of the procedure). There is also a concern that those who sponsor trials, those who analyze them, and those who set evidence-based guidelines using them sometimes have financial stakes in the outcome, which can cast doubts on the results. This is currently not a problem in economics but would surely become one if, as the advocates argue, successful RCTs became a precondition for the rollout of projects. Beyond that, John Concato, Nirav Shah, and Horwitz (2000) argue that, in practice, RCTs do not provide useful information beyond what can be learned from well-designed and carefully interpreted observational studies.

\section{Where Should We Go from Here?}

Cartwright (2007b) maintains a useful distinction between "hunting" causes and "using" them, and this section is about the use of randomized controlled trials for policy. Here I address the issue of generalizability or external validity - as opposed to internal validity as discussed in the previous section-grounds on which development RCTs are sometimes criticized (see, for example, Dani Rodrik 2009). We need to know when we can use local results, from instrumental variables, from RCTs, or from nonexperimental analyses, in contexts other than those in which they were obtained.

There are certainly cases in both medicine and economics where an RCT has had a major effect on the way that people think beyond the original local context of the trial. In the recent development literature, 
my favorite is Raghabendra Chattopadhyay and Duflo's (2004) study of women leaders in India. The Government of India randomly selected some panchayats and forced them to have female leaders, and the paper explores the differences in outcomes between such villages and others with male leaders. There is a theory (of sorts) underlying these experiments - the development community had briefly adopted the view that a key issue in development was the empowerment of women (or perhaps just giving them "voice") and, if this was done, more children would be educated, more money would be spent on food and on health, and so on. Women are altruistic and men are selfish. Chattopadhyay and Duflo's analysis of the Indian government's experiments shows that this is most likely wrong; I say most likely because, as with all experiments, the mechanisms are unclear. It is possible, for example, that women do indeed want the socially desirable outcomes but are unable to obtain them in a male dominated society, even when women are nominally in power. Even so, this study reversed previously held general beliefs. There are also many examples in medicine where knowledge of the mean treatment effect among the treated from a trial, even with some allowance for practical problems, has reversed previously held beliefs (see Davey Smith and Shah Ebrahim 2002, who note that "Observational studies propose, RCTs dispose").

Yet I also believe that RCTs of "what works," even when done without error or contamination, are unlikely to be helpful for policy, or to move beyond the local, unless they tell us something about why the program worked, something to which they are often neither targeted nor well-suited. Some of the issues are familiar and are widely discussed in the literature. Actual policy is always likely to be different from the experiment, for example because there are general equilibrium effects that operate on a large scale that are absent in a pilot, or because the outcomes are different when everyone is covered by the treatment rather than just a selected group of experimental subjects who are not representative of the population to be covered by the policy. Small development projects that help a few villagers or a few villages may not attract the attention of corrupt public officials because it is not worth their while to undermine or exploit them, yet they would do so as soon as any attempt were made to scale up. The scientists who run the experiments are likely to do so more carefully and conscientiously than would the bureaucrats in charge of a full scale operation. In consequence, there is no guarantee that the policy tested by the RCT will have the same effects as in the trial, even on the subjects included in the trial or in the population from which the trialists were selected. For an RCT to produce "useful knowledge" beyond its local context, it must illustrate some general tendency, some effect that is the result of mechanism that is likely to apply more broadly.

It is sometimes argued that skepticism about generalizability is simply "a version of David Hume's famous demonstration of the lack of a rational basis for induction" (Banerjee 2005, p. 4341). But what is going on here is often a good deal more mundane. Worrall (2007, p. 995) responds to the same argument with the following: "One example is the drug benoxaprophen (trade name: Opren), a nonsteroidal inflammatory treatment for arthritis and musculo-skeletal pain. This passed RCTs (explicitly restricted to 18 to 65 year olds) with flying colours. It is however a fact that musculo-skeletal pain predominately afflicts the elderly. It turned out, when the (on average older) 'target population' were given Opren, there were a significant number of deaths from hepato-renal failure and the drug was withdrawn."

In the same way, an educational protocol that was successful when randomized across 
villages in India holds many things constant that would not be constant if the program were transported to Guatemala or Vietnam, even as a randomized controlled trial, let alone when enacted into policy (Cartwright 2010). These examples demonstrate a failure to control for relevant factors or nonrandom participation in the trial, not the general impossibility of induction. RCTs, like nonexperimental results, cannot automatically be extrapolated outside the context in which they were obtained.

Perhaps the most famous randomization in development economics is Progresa (now Oportunidades) in Mexico, a conditional cash transfer scheme in which welfare benefits to parents were paid conditional on their children attending schools and clinics. Angrist and Pischke (2010) approvingly quote Paul Gertler's statement that "Progresa is why now thirty countries worldwide have conditional cash transfer programs," and there is no doubt that the spread of Progresa depended on the fact that its successes were supported by a randomized evaluation. Yet it is unclear that this wholesale imitation is a good thing. Santiago Levy (2006), the architect of Progresa, notes that the Mexican scheme cannot simply be exported to other countries if, for example, those countries have a preexisting antipoverty program with which conditional cash transfers might not fit, or if they do not have the capacity to meet the additional demand for education or healthcare, or if the political support is absent. Incentivizing parents to take their children to clinics will not improve child health if there are no clinics to serve them, a detail that can easily be overlooked in the enthusiasm for the credibility of the Mexican evaluation.

Pawson and Tilley (1997) argue that it is the combination of mechanism and context that generates outcomes and that, without understanding that combination, scientific progress is unlikely. Nor can we safely go from experiments to policy. In economics, the language would refer to theory, building models, and tailoring them to local conditions. Policy requires a causal model; without it, we cannot understand the welfare consequences of a policy, even a policy where causality is established and that is proven to work on its own terms. Banerjee (2007a) describes an RCT by Duflo, Rema Hanna, and Stephen Ryan (2008) as "a new economics being born." This experiment used cameras to monitor and prevent teacher absenteeism in villages in the Indian state of Rajasthan. Curiously, Pawson and Tilley (1997, pp. 78-82) use the example of cameras (to deter crime in car parks) as one of their running examples. They note that cameras do not, in and of themselves, prevent crime because they do not make it impossible to break into a car. Instead, they depend on triggering a series of behavioral changes. Some of those changes show positive experimental outcomes - crime is down in the car parks with cameras-but are undesirable, for example because crime is shifted to other car parks or because the cameras change the mix of patrons of the car park. There are also cases where the experiment fails but has beneficial effects. It would not be difficult to construct similar arguments for the cameras in the Indian schools, and welfare conclusions cannot be supported unless we understand the behavior of teachers, pupils, and their parents. Duflo, Hanna, and Ryan (2008) understand this and use their experimental results to construct a model of teacher behavior. Other papers that use structural models to interpret experimental results include Petra E. Todd and Kenneth I. Wolpin (2006) and Orazio Attanasio, Costas Meghir, and Ana Santiago (2005); these and the other studies reviewed in Todd and Wolpin (forthcoming) are surely a good avenue for future explanation.

Cartwright (2007a) draws a contrast between the rigor applied to establish 
internal validity-to establish the gold standard status of RCTs - and the much looser arguments that are used to defend the transplantation of the experimental results to policy. For example, running RCTs to find out whether a project works is often defended on the grounds that the experimental project is like the policy that it might support. But the "like" is typically argued by an appeal to similar circumstances, or a similar environment, arguments that depend entirely on observable variables. Yet controlling for observables is the key to the matching estimators that are one of the main competitors for RCTs and that are typically rejected by the advocates of RCTs on the grounds that RCTs control not only for the things that we observe but things that we cannot. As Cartwright notes, the validity of evidence-based policy depends on the weakest link in the chain of argument and evidence, so that by the time we seek to use the experimental results, the advantage of RCTs over matching or other econometric methods has evaporated. In the end, there is no substitute for careful evaluation of the chain of evidence and reasoning by people who have the experience and expertise in the field. The demand that experiments be theory-driven is, of course, no guarantee of success, though the lack of it is close to a guarantee of failure.

It is certainly not always obvious how to combine theory with experiments. Indeed, much of the interest in RCTs - and in instrumental variables and other econometric techniques that mimic random allocation-comes from a deep skepticism of economic theory, and impatience with its ability to deliver structures that seem at all helpful in interpreting reality. Applied and theoretical economists seem to be further apart now than at any period in the last quarter century. Yet failure to reintegrate is hardly an option because without it there is no chance of long-term scientific progress or of maintaining and extending the results of experimentation. RCTs that are not theoretically guided are unlikely to have more than local validity, a warning that applies equally to nonexperimental work. In Angus Deaton (forthcoming), where I develop these arguments further, I discuss a number of examples of nonexperimental work in economic development where theories are developed to the point where they are capable of being tested on nonexperimental data, with the results used to refute, refine, or further develop the theory. Randomized experiments, which allow the researcher to induce controlled variance, should be a powerful tool in such programs, and make it possible to construct tests of theory that might otherwise be difficult or impossible. The difference is not in the methods, experimental and nonexperimental, but in what is being investigated, projects on the one hand, and mechanisms on the other.

One area in which this is already happening is in behavioral economics, and the merging of economics and psychology, whose own experimental tradition is clearly focused on behavioral regularities. The experiments reviewed in Steven D. Levitt and John A. List (2008), often involving both economists and psychologists, cover such issues as loss aversion, procrastination, hyperbolic discounting, or the availability heuristic - all of which are examples of behavioral mechanisms that promise applicability beyond the specific experiments. There also appears to be a good deal of convergence between this line of work, inspired by earlier experimental traditions in economic theory and in psychology, and the most recent work in development. Instead of using experiments to evaluate projects, looking for which projects work, this development work designs its experiments to test predictions of theories that are generalizable to other situations. Without any attempt to be comprehensive, some examples are Dean Karlan and Jonathan Zinman (2008), who 
are concerned with the price elasticity of the demand for credit; Marianne Bertrand et al. (2010), who take predictions about the importance of context from the psychology laboratory to the study of advertising for small loans in South Africa; Duflo, Kremer, and Jonathan Robinson (2009), who construct and test a behavioral model of procrastination for the use of fertilizers by small farmers in Kenya; and Xavier Giné, Karlan, and Zinman (2009), who use an experiment in the Philippines to test the efficacy of a smoking-cessation product designed around behavioral theory. In all of this work, the project, when it exists at all, is an embodiment of the theory that is being tested and refined, not the object of evaluation in its own right, and the field experiments are a bridge between the laboratory and the analysis of "natural" data (List 2006). The collection of purpose-designed data and the use of randomization often make it easier to design an acid test that can be more difficult to construct without them. If we are lucky, this work will provide the sort of behavioral realism that has been lacking in much of economics while, at the same time, identifying and allowing us to retain the substantial parts of existing economic theory that are genuinely useful.

In this context, it is worth looking back to the previous phase of experimentation in economics that started with the New Jersey income tax experiments. A rationale for these experiments is laid out in Guy H. Orcutt and Alice G. Orcutt (1968) in which the vision is a formal model of labor supply with the experiments used to estimate its parameters. By the early 1990s, however, experimentation had moved on to a "what works" basis, and Manski and Irwin Garfinkel (1992), surveying the experience, write "there is, at present, no basis for the popular belief that extrapolation from social experiments is less problematic than extrapolation from observational data. As we see it, the recent embrace of reduced-form social experimentation to the exclusion of structural evaluation based on observational data is not warranted." Their statement still holds good, and it would be worth our while trying to return to something like Orcutt and Orcutt's vision in experimental work, as well as to reestablishing the relevance and importance of theorydriven nonexperimental work. The more recent Moving to Opportunity experiment is another example of an experiment that was more successful as a black-box test of "what works," in this case giving housing vouchers to a small segment of the most disadvantaged population, than it was in illuminating general long-standing questions about the importance of neighborhoods (Sampson 2008). Sampson concludes his review of the Moving to Opportunity experiment with "a plea for the old-fashioned but time-proven benefits of theoretically motivated descriptive research and synthetic analytical efforts" (p. 227).

Finally, I want to return to the issue of "heterogeneity," a running theme in this paper. Heterogeneity of responses first appeared in section 2 as a technical problem for instrumental variable estimation, dealt with in the literature by local average treatment estimators. Randomized controlled trials provide a method for estimating quantities of interest in the presence of heterogeneity, and can therefore be seen as another technical solution for the "heterogeneity problem." They allow estimation of mean responses under extraordinarily weak conditions. But as soon as we deviate from ideal conditions and try to correct the randomization for inevitable practical difficulties, heterogeneity again rears its head, biasing estimates, and making it difficult to interpret what we get. In the end, the technical fixes fail and compromise our attempts to learn from the data. What this should tell us is that the heterogeneity is not a technical problem but a symptom of something deeper, which 
is the failure to specify causal models of the processes we are examining. Technique is never a substitute for the business of doing economics.

Perhaps the most successful example of learning about economic development is the Industrial Revolution in Britain, recently described by Joel Mokyr (2009). Much of the learning was indeed accomplished by trial and error-RCTs were yet to be inventedthough the practical and often uneducated people who did the experimentation were constantly in contact with leading scientists, often through hundreds of local societies dedicated to the production of "useful knowledge" and its application to the benefit of mankind (see also Roy Porter 2000). Mokyr sees the Enlightenment as a necessary precondition for the revolution and of the escape from poverty and disease. Yet the application and development of scientific ideas was uneven, and progress was faster where there was less heterogeneity, for example in chemical or mechanical processes, which tended to work in much the same way everywhere, than where heterogeneity was important, as in agriculture, where soils and farms differed by the mile (Mokyr 2009, p. 192). Even so, as with sanitation, progress was often made without a correct understanding of mechanisms and with limited or no experimentation; Richard J. Murnane and Richard R. Nelson (2007) argue that the same is frequently true in modern medicine. In the end, many problems were simply too hard to be solved without theoretical guidance, which in areas such as soil chemistry, or the germ theory of disease, lay many decades in the future. It took scientific understanding to overcome the heterogeneity of experience which ultimately defeats trial and error. As was the case then, so now, and I believe that we are unlikely to banish poverty in the modern world by trials alone, unless those trials are guided by and contribute to theoretical understanding.

\section{REFERENCES}

-Acemoglu, Daron, Simon Johnson, and James A. Robinson. 2001. "The Colonial Origins of Comparative Development: An Empirical Investigation." American Economic Review, 91(5): 1369-1401.

-Altman, Douglas G. 1998. "Within Trial Variation-A False Trail?" Journal of Clinical Epidemiology, 51(4): 301-03.

Angrist, Joshua D. 1990. "Lifetime Earnings and the Vietnam Era Draft Lottery: Evidence from Social Security Administrative Records." American Economic Review, 80(3): 313-36.

-Angrist, Joshua D., and Victor Lavy. 1999. "Using Maimonides' Rule to Estimate the Effect of Class Size on Scholastic Achievement." Quarterly Journal of Economics, 114(2): 533-75.

-Angrist, Joshua D., and Jörn-Steffen Pischke. 2010. "The Credibility Revolution in Empirical Economics: How Better Research Design is Taking the Con Out of Econometrics." Journal of Economic Perspectives, 24(2): 3-30.

Attanasio, Orazio, Costas Meghir, and Ana Santiago. 2005. "Education Choices in Mexico: Using a Structural Model and a Randomized Experiment to Evaluate Progresa.” Unpublished.

Banerjee, Abhijit Vinayak. 2005. “New Development Economics' and the Challenge to Theory." Economic and Political Weekly, 40(40): 4340-44.

Banerjee, Abhijit Vinayak. 2007a. "Inside the Machine: Toward a New Development Economics." Boston Review, 32(2): 12-18.

Banerjee, Abhijit Vinayak. 2007b. Making Aid Work. Cambridge and London: MIT Press.

Banerjee, Abhijit Vinayak, and Ruimin He. 2008. "Making Aid Work." In Reinventing Foreign Aid, ed. William Easterly, 47-92. Cambridge and London: MIT Press.

Barro, Robert J. 1998. Determinants of Economic Growth: A Cross-Country Empirical Study. Cambridge and London: MIT Press.

Barro, Robert J., and Xavier Sala-i-Martin. 1995. Economic Growth. New York; London and Montreal: McGraw-Hill.

Bauer, P. T. 1971. Dissent on Development: Studies and Debates in Development Economics. London: Weidenfeld and Nicolson.

Bauer, P. T. 1981. Equality, the Third World and Economic Delusion. Cambridge and London: Harvard University Press.

-Bertrand, Marianne, Dean Karlan, Sendhil Mullainathan, Eldar Shafir, and Jonathan Zinman. 2010. "What's Advertising Content Worth? Evidence from a Consumer Credit Marketing Field Experiment." Quarterly Journal of Economics, 125(1): 263-305.

Blundell, Richard, and Monica Costa Dias. 2009. "Alternative Approaches to Evaluation in Empirical Microeconomics." Journal of Human Resources, 44(3): 565-640.

Boone, Peter. 1996. "Politics and the Effectiveness of Foreign Aid." European Economic Review, 40(2): 289-329. 
- Burnside, Craig, and David Dollar. 2000. "Aid, Policies, and Growth." American Economic Review, 90(4): 847-68.

Card, David. 1999. "The Causal Effect of Education on Earnings." In Handbook of Labor Economics, Volume 3A, ed. Orley Ashenfelter and David Card, 1801-63. Amsterdam; New York and Oxford: Elsevier Science, North-Holland.

Cartwright, Nancy. 2007a. "Are RCTs the Gold Standard?” Biosocieties, 2(1): 11-20.

Cartwright, Nancy. 2007b. Hunting Causes and Using Them: Approaches in Philosophy and Economics. Cambridge and New York: Cambridge University Press.

Cartwright, Nancy. 2010. "What Are Randomised Controlled Trials Good For?" Philosophical Studies, 147(1): 59-70.

Chattopadhyay, Raghabendra, and Esther Duflo. 2004. "Women as Policy Makers: Evidence from a Randomized Policy Experiment in India." Econometrica, 72(5): 1409-43.

Clemens, Michael, Steven Radelet, and Rikhil Bhavnani. 2004. "Counting Chickens When They Hatch: The Short Term Effect of Aid on Growth." Center for Global Development Working Paper 44.

Concato, John, Nirav Shah, and Ralph I. Horwitz. 2000. "Randomized, Controlled Trials, Observational Studies, and the Hierarchy of Research Designs." New England Journal of Medicine, 342(25): 1887-92.

Cox, David R. 1958. Planning of Experiments. New York: Wiley.

Dalgaard, Carl-Johan, and Henrik Hansen. 2001. "On Aid, Growth and Good Policies.” Journal of Development Studies, 37(6): 17-41.

-Dalgaard, Carl-Johan, Henrik Hansen, and Finn Tarp. 2004. "On the Empirics of Foreign Aid and Growth." Economic Journal, 114(496): F191-216.

DDavey Smith, George, and Shah Ebrahim. 2002. "Data Dredging, Bias, or Confounding: They Can All Get You into the BMJ and the Friday Papers." British Medical Journal, 325: 1437-38.

Davey Smith, George, and Matthias Egger. 1998. "Incommunicable Knowledge? Interpreting and Applying the Results of Clinical Trials and Metaanalyses." Journal of Clinical Epidemiology, 51(4): 289-95.

Deaton, Angus. Forthcoming. "Understanding the Mechanisms of Economic Development." Journal of Economic Perspectives.

$\checkmark$ de Mel, Suresh, David McKenzie, and Christopher Woodruff. 2008. "Returns to Capital in Microenterprises: Evidence from a Field Experiment." Quarterly Journal of Economics, 123(4): 1329-72.

Duflo, Esther. 2004. "Scaling Up and Evaluation." In Annual World Bank Conference on Development Economics, 2004: Accelerating Development, ed. François Bourguignon and Boris Pleskovic, 341-69. Washington, D.C.: World Bank; Oxford and New York: Oxford University Press.

Duflo, Esther, Rachel Glennerster, and Michael Kremer. 2008. "Using Randomization in Development
Economics Research: A Toolkit." In Handbook of Development Economics, Volume 4, ed. T. Paul Schultz and John Strauss, 3895-3962. Amsterdam and Oxford: Elsevier, North-Holland.

Duflo, Esther, Rema Hanna, and Stephen Ryan. 2008. "Monitoring Works: Getting Teachers to Come to School." Center for Economic and Policy Research Discussion Paper 6682.

Duflo, Esther, Michael Kremer, and Jonathan Robinson. 2009. "Nudging Farmers to Use Fertilizer: Evidence from Kenya." National Bureau of Economic Research Working Paper 15131.

Duflo, Esther, and Rohini Pande. 2007. "Dams." Quarterly Journal of Economics, 122(2): 601-46.

Easterly, William. 2006. The White Man's Burden: Why the West's Efforts to Aid the Rest Have Done So Much Ill and So Little Good. New York: Penguin Press.

Easterly, William, ed. 2008. Reinventing Foreign Aid. Cambridge and London: MIT Press.

-Easterly, William. 2009. "Can the West Save Africa?" Journal of Economic Literature, 47(2): 373-447.

-Easterly, William, Ross Levine, and David Roodman. 2004. "Aid, Policies, and Growth: Comment." American Economic Review, 94(3): 774-80.

Fisher, Ronald A. 1935. The Design of Experiments, Eighth edition. New York: Hafner, 1960.

Freedman, David A. 2005. Statistical Models: Theory and Practice. Cambridge and New York: Cambridge University Press.

-Freedman, David A. 2006. "Statistical Models for Causation: What Inferential Leverage Do They Provide?" Evaluation Review, 30(6): 691-713.

-Freedman, David A. 2008. "On Regression Adjustments to Experimental Data." Advances in Applied Mathematics, 40(2): 180-93.

Giné, Xavier, Dean Karlan, and Jonathan Zinman. 2009. "Put Your Money Where Your Butt Is: A Commitment Contract for Smoking Cessation." World Bank Policy Research Working Paper 4985.

-Glewwe, Paul, Michael Kremer, Sylvie Moulin, and Eric Zitzewitz. 2004. "Retrospective vs. Prospective Analyses of School Inputs: The Case of Flip Charts in Kenya." Journal of Development Economics, 74(1): 251-68.

Groopman, Jerome. 2009. "Diagnosis: What Doctors Are Missing." New York Review of Books, 56(17), November 5 th.

Guillaumont, Patrick, and Lisa Chauvet. 2001. "Aid and Performance: A Reassessment.” Journal of Development Studies, 37(6): 66-92.

-Hansen, Henrik, and Finn Tarp. 2000. “Aid Effectiveness Disputed." Journal of International Development, 12(3): 375-98.

-Hansen, Henrik, and Finn Tarp. 2001. "Aid and Growth Regressions." Journal of Development Economics, 64(2): 547-70.

Heckman, James J. 1992. "Randomization and Social Policy Evaluation." In Evaluating Welfare and Training Programs, ed. Charles F. Manski and Irwin Garfinkel, 201-30. Cambridge and London: Harvard University Press. Available as National Bureau of 
Economic Research Technical Working Paper 107.

-Heckman, James J. 1997. "Instrumental Variables: A Study of Implicit Behavioral Assumptions Used in Making Program Evaluations." Journal of Human Resources, 32(3): 441-62.

-Heckman, James J. 2000. "Causal Parameters and Policy Analysis in Economics: A Twentieth Century Retrospective." Quarterly Journal of Economics, 115(1): 45-97.

Heckman, James J., and Jeffrey A. Smith. 1995. "Assessing the Case for Social Experiments." Journal of Economic Perspectives, 9(2): 85-110.

Heckman, James J., and Sergio Urzua. 2009. "Comparing IV with Structural Models: What Simple IV Can and Cannot Identify." National Bureau of Economic Research Working Paper 14706.

-Heckman, James J., Sergio Urzua, and Edward Vytlacil. 2006. "Understanding Instrumental Variables in Models with Essential Heterogeneity." Review of Economics and Statistics, 88(3): 389-432.

-Heckman, James J., and Edward Vytlacil. 1999. "Local Instrumental Variables and Latent Variable Models for Identifying and Bounding Treatment Effects." Proceedings of the National Academy of Sciences, 96(8): 4730-34.

Heckman, James J., and Edward Vytlacil. 2007. "Econometric Evaluation of Social Programs, Part II: Using the Marginal Treatment Effect to Organize Alternative Econometric Estimators to Evaluate Social Programs, and to Forecast their Effects in New Environments." In Handbook of Econometrics, Volume 6B, ed. James J. Heckman and Edward E. Leamer, 4875-5143. Amsterdam and Oxford: Elsevier, North-Holland.

- Horwitz, Ralph I., Burton H. Singer, Robert W. Makuch, and Catherine M. Viscoli. 1996. "Can Treatment That is Helpful on Average Be Harmful to Some Patients? A Study of the Conflicting Information Needs of Clinical Inquiry and Drug Regulation." Journal of Clinical Epidemiology, 49(4): 395-400.

-Horwitz, Ralph I., Burton H. Singer, Robert W. Makuch, and Catherine M. Viscoli. 1997. "On Reaching the Tunnel at the End of the Light." Journal of Clinical Epidemiology, 50(7): 753-55.

-Hoxby, Caroline M. 2000. "Does Competition among Public Schools Benefit Students and Taxpayers?" American Economic Review, 90(5): 1209-38.

Imbens, Guido W. 2009. "Better Late than Nothing: Some Comments on Deaton (2009) and Heckman and Urzua (2009)." National Bureau of Economic Research Working Paper 14896.

-Imbens, Guido W., and Joshua D. Angrist. 1994. "Identification and Estimation of Local Average Treatment Effects." Econometrica, 62(2): 467-75.

International Initiative for Impact Evaluation (3IE). 2008. http://www.3ieimpact.org/.

Jurajda, Štěpán, and Daniel Münich. 2009. "Admission to Selective Schools, Alphabetically." http://home. cerge-ei.cz/jurajda/alphabet07.pdf.

-Kanbur, Ravi. 2001. "Economic Policy, Distribution and Poverty: The Nature of Disagreements." World
Development, 29(6): 1083-94.

-Karlan, Dean, and Jonathan Zinman. 2008. "Credit Elasticities in Less-Developed Economies: Implications for Microfinance." American Economic Review, 98(3): 1040-68.

-Leamer, Edward E. 1985. "Vector Autoregressions for Causal Inference?" Carnegie-Rochester Conference Series on Public Policy, 22: 255-303.

Lee, David S., and Thomas Lemieux. 2009. "Regression Discontinuity Designs in Economics." National Bureau of Economic Research Working Paper 14723.

Lensink, Robert, and Howard White. 2001. "Are There Negative Returns to Aid?" Journal of Development Studies, 37(6): 42-65.

Leonhardt, David. 2008. "Making Economics Relevant Again.” New York Times, February 20.

Levitt, Steven D., and John A. List. 2008. "Field Experiments in Economics: The Past, the Present, and the Future." National Bureau of Economic Research Working Paper 14356.

Levy, Santiago. 2006. Progress against Poverty: Sustaining Mexico's Progresa-Oportunidades Program. Washington, D.C.: Brookings Institution Press.

List, John A. 2006. "Field Experiments: A Bridge between Lab and Naturally Occurring Data." B.E. Journal of Economic Analysis and Policy: Advances in Economic Analysis and Policy, 6(2).

- Mankiw, N. Gregory, David Romer, and David N. Weil. 1992. "A Contribution to the Empirics of Economic Growth." Quarterly Journal of Economics, 107(2): 407-37.

-Manski, Charles F. 1996. "Learning About Treatment Effects from Experiments with Random Assignment of Treatments." Journal of Human Resources, 31(4): 709-33.

Manski, Charles F., and Irwin Garfinkel. 1992. "Evaluating Welfare and Training Programs: Introduction.” In Evaluating Welfare and Training Programs, ed. Charles F. Manski and Irwin Garfinkel, 1-22. Cambridge and London: Harvard University Press.

McCleary, Rachel M., and Robert J. Barro. 2006. "Religion and Economy." Journal of Economic Perspectives, 20(2): 49-72.

McCrary, Justin. 2008. "Manipulation of the Running Variable in the Regression Discontinuity Design: A Density Test." Journal of Econometrics, 142(2): 698-714.

-Miguel, Edward, and Michael Kremer. 2004. "Worms: Identifying Impacts on Education and Health in the Presence of Treatment Externalities." Econometrica, 72(1): 159-217.

- Miguel, Edward, Shanker Satyanath, and Ernest Sergenti. 2004. "Economic Shocks and Civil Conflict: An Instrumental Variables Approach.” Journal of Political Economy, 112(4): 725-53.

Mokyr, Joel. 2009. The Enlightened Economy: An Economic History of Britain 1700-1850. New Haven and London: Yale University Press.

- Murnane, Richard J., and Richard R. Nelson. 2007. "Improving the Performance of the Education Sector: The Valuable, Challenging, and Limited Role 
of Random Assignment Evaluations." Economics of Innovation and New Technology, 16(5): 307-22.

Orcutt, Guy H., and Alice G. Orcutt. 1968. "Incentive and Disincentive Experimentation for Income Maintenance Policy Purposes." American Economic Review, 58(4): 754-72.

Pawson, Ray, and Nick Tilley. 1997. Realistic Evaluation. London and Thousand Oaks, Calif.: Sage Publications.

- Peto, Richard, Rory Collins, and Richard Gray. 1995. "Large-Scale Randomized Evidence: Large, Simple Trials and Overviews of Trials." Journal of Clinical Epidemiology, 48(1): 23-40.

-Pogge, Thomas. 2005. "World Poverty and Human Rights." Ethics and International Affairs, 19(1): 1-7.

Porter, Roy. 2000. The Creation of the Modern World: The Untold Story of the British Enlightenment. New York and London: Norton.

Poverty Action Lab. 2007. "Clinton Honors Global Deworming Effort." http://www.povertyactionlab. org/deworm/.

- Rajan, Raghuram G., and Arvind Subramanian. 2008. "Aid and Growth: What Does the Cross-Country Evidence Really Show?" Review of Economics and Statistics, 90(4): 643-65.

Reiss, Peter C., and Frank A. Wolak. 2007. "Structural Econometric Modeling: Rationales and Examples from Industrial Organization." Handbook of Econometrics, Volume 6A, ed. James J. Heckman and Edward E. Leamer, 4277-4415. Amsterdam and Oxford: Elsevier, North-Holland.

Rodrik, Dani. 2009. "The New Development Economics: We Shall Experiment, but How Shall We Learn?" In What Works in Development? Thinking Big and Thinking Small, ed. Jessica Cohen and William Easterly, 24-47. Washington, D.C.: Brookings Institution Press.

-Roodman, David. 2007. "The Anarchy of Numbers: Aid, Development, and Cross-Country Empirics." World Bank Economic Review, 21(2): 255-77.

Sachs, Jeffrey D. 2005. The End of Poverty: Economic Possibilities for Our Time. New York: Penguin.

Sachs, Jeffrey D. 2008. Common Wealth: Economics for a Crowded Planet. New York: Penguin Press.

-Sampson, Robert J. 2008. "Moving to Inequality: Neighborhood Effects and Experiments Meet Social Structure." American Journal of Sociology, 114(1): $189-231$.

Sanbonmatsu, Lisa, Jeffrey R. Kling, Greg J. Duncan, and Jeanne Brooks-Gunn. 2006. "Neighborhoods and Academic Achievement: Results from the Moving to Opportunity Experiment." Journal of Human Resources, 41(4): 649-91.

-Senn, Stephen, and Frank Harrell. 1997. “On Wisdom after the Event." Journal of Clinical Epidemiology, 50(7): 749-51.

-Sims, Christopher A. 2010. "But Economics Is Not an Experimental Science." Journal of Economic Perspectives, 24(2): 59-68.

Singer, Peter. 2004. One World: The Ethics of Globalization. New Haven and London: Yale University Press, 2002.

The Lancet. 2004. "The World Bank Is Finally Embracing Science: Editorial.” The Lancet, 364: 731-32.

-Todd, Petra E., and Kenneth I. Wolpin. 2006. “Assessing the Impact of a School Subsidy Program in Mexico: Using a Social Experiment to Validate a Dynamic Behavioral Model of Child Schooling and Fertility." American Economic Review, 96(5): 1384-1417.

Todd, Petra E., and Kenneth I. Wolpin. Forthcoming. "Structural Estimation and Policy Evaluation in Developing Countries." Annual Review of Economics.

-Urquiola, Miguel, and Eric Verhoogen. 2009. "ClassSize Caps, Sorting, and the Regression-Discontinuity Design.” American Economic Review, 99(1): 179-215.

van den Berg, Gerard. 2008. "An Economic Analysis of Exclusion Restrictions for Instrumental Variable Estimation." Unpublished.

-Wennberg, David E., F. L. Lucas, John D. Birkmeyer, Carl E. Bredenberg, and Elliott S. Fisher. 1998. "Variation in Carotid Endarterectomy Mortality in the Medicare Population: Trial Hospitals, Volume, and Patient Characteristics." Journal of the American Medical Association, 279(16): 1278-81.

Wooldridge, Jeffrey M. 2002. Econometric Analysis of Cross Section and Panel Data. Cambridge and London: MIT Press.

World Bank. 2008. "Spanish Impact Evaluation Fund." http://web.worldbank.org/WBSITE/EXTERNAL/ TOPICS/EXTPOVERTY/EXTISPMA/0,,contentM DK:21419502 menuPK:384336 pagePK:148956 p iPK:216618 theSitePK:384329,00.html.

-Worrall, John. 2007. "Evidence in Medicine and Evidence-Based Medicine.” Philosophy Compass, 2(6): 981-1022. 


\section{This article has been cited by:}

1. Henk Folmer, Olof Johansson-Stenman. 2011. Does Environmental Economics Produce Aeroplanes Without Engines? On the Need for an Environmental Social Science. Environmental and Resource Economics . [CrossRef]

2. C. B. Barrett, M. R. Carter. 2010. The Power and Pitfalls of Experiments in Development Economics: Some Non-random Reflections. Applied Economic Perspectives and Policy 32:4, 515-548. [CrossRef]

3. M. Ehmke, J. F. Shogren. 2010. The Experimental Mindset within Development Economics: Proper Use and Handling Are Everything. Applied Economic Perspectives and Policy 32:4, 549-563. [CrossRef]

4. Andrew Dillon. 2010. Do Differences in the Scale of Irrigation Projects Generate Different Impacts on Poverty and Production?. Journal of Agricultural Economics no-no. [CrossRef]

5. Angus Deaton, . 2010. Understanding the Mechanisms of Economic DevelopmentUnderstanding the Mechanisms of Economic Development. Journal of Economic Perspectives 24:3, 3-16. [Abstract] [View $\mathrm{PDF}$ article] [PDF with links] 